\title{
Minimally invasive surgery and cancer: controversies part 1
}

\author{
Melanie Goldfarb · Steven Brower • \\ S. D. Schwaitzberg
}

Received: 27 March 2009/Accepted: 14 May 2009/Published online: 2 July 2009

(c) The Author(s) 2009. This article is published with open access at Springerlink.com

\begin{abstract}
Perhaps there is no more important issue in the care of surgical patients than the appropriate use of minimally invasive surgery (MIS) for patients with cancer. Important advances in surgical technique have an impact on early perioperative morbidity, length of hospital stay, pain management, and quality of life issues, as clearly proved with MIS. However, for oncology patients, historically, the most important clinical questions have been answered in the context of prospective randomized trials. Important considerations for MIS and cancer have been addressed, such as what are the important immunologic consequences of MIS versus open surgery and what is the role of laparoscopy in the staging of gastrointestinal cancers? This review article discusses many of the key controversies in the minimally invasive treatment of cancer using the pro-con debate format.
\end{abstract}

Keywords Cancer - Immunologic consequences ·

Laparoscopy $\cdot$ Minimally invasive surgery

Perhaps there is no more important issue in the care of surgical patients than the appropriate use of minimally invasive surgery (MIS) for cancer patients. Important advances in surgical technique have an impact on early

M. Goldfarb

Beth Israel Deaconess Medical Center, Boston, MA, USA

S. Brower

Memorial Health University Medical Center, Savanna, GA, USA

S. D. Schwaitzberg $(\bowtie)$

Department of Surgery, Cambridge Health Alliance,

Cambridge, MA, USA

e-mail: SSchwaitzberg@CHalliance.org perioperative morbidity, length of hospital stay, pain management, and quality of life issues, as clearly proved with MIS. However, for oncology patients, historically, the most important clinical questions have been answered in the context of prospective randomized trials. Important considerations for MIS and cancer have been addressed such as what are the important immunologic consequences of MIS versus open surgery and what is the role of laparoscopy in the staging of gastrointestinal (GI) cancers? Until recently, the role of prospective randomized trials has been absent.

The era of landmark clinical trials for MIS and cancer recently changed with the completion of the Clinical Outcomes of Surgical Therapy (COST) trial, which randomized 872 patients with colonic adenocarcinoma to open versus laparoscopically assisted colectomy. This landmark trial demonstrated that the two groups were not significantly different in terms of local and overall survival at 3 years. Similarly, the European Colon Cancer Laparoscopic or Open Resection study group trial (CCLOR) compared results for colon cancer between laparoscopic and open surgery. There also was no difference between the two groups with respect to morbidity and mortality. To date, the long-term oncologic outcomes from the CCLOR trial have not been reported. These trials have led the way for historical reconsideration of the utility of MIS surgery for cancer.

This symposium, entitled Minimally Invasive Surgery and Cancer, presented at the Society of American Gastrointestinal and Endoscopic Surgeons (SAGES) annual meeting in 2007, reviewed the important controversies involved in the staging and treatment of gastrointestinal, colorectal, hepatobiliary, and endocrine surgery. The debate examines the most important topics, contrasting technical considerations for MIS surgery used to treat adult and pediatric esophageal, gastric, pancreatic, hepatic, colorectal, and adrenal neoplasms. Specific topics debated 
include Immunologic Differences Between Open and MIS Cancer, Perioperative Morbidity and Mortality for MIS Versus Open GI Cancer Surgery, The Role of Perioperative Staging for Esophageal and Gastric Cancer, and various MIS treatment methods for these disease sites.

The authors believe that this is the most comprehensive compendium of controversial questions related to MIS and gastrointestinal surgery to date. Although the debates form the basis for important prospective randomized clinical trials to answer these questions, significant attention has been directed toward evidenced-based data supporting the diverse opinions put forth in the debates.

Finally, the debate questions arose from an important project of the Research Committee of SAGES known as the Delphi Project. This committee sought to ascertain the most important MIS questions of concern to the members of SAGES. Many of the most important questions that members considered unanswered to date and of most interest to the constituency were those related to the appropriate use of MIS in cancer cases. As such, this debate on MIS and cancer was conceived based on the membership's interest in the topic.

\section{The controversy: do meaningful immunologic differences exist between open and MIS cancer surgery?}

Pro: Immunosuppression in open oncologic surgery is not a problem

\section{Lawrence Wagman}

Director of the Liver Tumor Program at City of Hope Hospital, Duate, CA, USA

"The world hates change, but it is the only thing that has brought progress"-Charles Kettering

"Just because you can measure something, doesn't mean it amounts to anything"-Anonymous

Many hypotheses exist regarding immunosuppression and surgery:

1. There is an immunologic response to surgery.

2. The response with laparoscopy differs from that with open surgery.

3. The differential response can be measured.

4. The impact of the differential can be measured.

5. The impact is "important."

What does important mean? It means that data are not only statistically significant, not just presentable, not just publishable, or not just true in a murine model. It means that data have real and human clinical significance. Important measurable indicators are overall outcome, length of hospital stay, pain, infections, cost, local and systemic recurrence rates, and survival rates. To prove any of these hypotheses, studies must be prospective and randomized, must have meaningful end points and blinding of investigators, and must show statistical significance and present scientific (intellectual) consistency.

What effect does pneumoperitoneum have on the inflammatory response? To date, most of the work in this area has been done with animal models. In 2006, Fuentes et al. [1] published a study showing a survival benefit for rats with carbon dioxide $\left(\mathrm{CO}_{2}\right)$ pneumoperitoneum compared with control animals at $48 \mathrm{~h}$, with interleukin-6 (IL6) levels attenuated using a $\mathrm{CO}_{2}$ pneumoperitoneum. In 2004, Bachman et al. [2] demonstrated that $\mathrm{CO}_{2}$ insufflation reduces the inflammatory response in rats based on reduced levels of alpha-2 macroglobulin mRNA and beta fibrinogen. Yet another rat model, described in a 2001 paper by Mendoza-Sagaon et al. [3] showed that a transient suppression of delayed-type hypersensitivity (DTH) did not occur in animals with a Nissen fundoplication performed laparoscopically using $\mathrm{CO}_{2}$ pneumoperitoneum compared with open control subjects.

The laparoscopic cholecystectomy that propelled laparoscopy into the mainstream in the early 1990s was the focus of numerous trials seeking an improvement in clinical variables [4]. In 1994, Steiner et al. [5] examined data from 34 hospitals in Maryland from 1985 to 1992 . He reported a decline in operative mortality from 0.84 to 0.56 overall, with an odds ratio of 0.22 favoring the laparoscopic approach for decreased mortality and with a $95 \%$ confidence interval of 0.13 to 0.37 . A main criticism of this study, however, was the heterogenicity of the comparative patient populations. Those receiving the laparoscopic surgery were younger and had less acute disease not as frequently complicated by common bile duct (CBD) stones. A higher percentage of these patients were white and more likely to have health maintenance organization (HMO) or private insurance.

\section{Summary of studies}

The response to sepsis is reduced in laparoscopic surgery, both the inflammatory response and the ability to maintain DTH [6].

A review of more than 10 articles shows no significant difference in wound, urinary, or lung infection rates between the two approaches [7-10]. Although some findings suggest a higher rate of anastomotic leak with the laparoscopic than with the open technique, this is most likely explained by the learning curve and thus related to operator experience. Earlier reports suggested slightly higher local failure rates and higher port-site implantation with laparoscopic oncologic surgery [8].

More recent studies currently demonstrate equivalent rates for the colon and nearly equivalent rates for rectal 
cancer recurrences, likely a reflection of early-era technical factors $[9,10]$. Numerous studies demonstrate equivalent survival rates between laparoscopic and open cancer surgery, although an occasional study shows benefit for either the laparoscopic or open approach.

In conclusion, laparoscopy is an excellent modern intraabdominal surgery technique for malignancy. Technical aspects and operator skill define organs best addressed with the laparoscopic versus the open technique. Using clinical end points, it can be shown that immunologic factors have no role in the decision to perform these operations, with preference for open rather than laparoscopic procedure.

\section{Con: Laparoscopic surgery for cancer reduces adverse immunologic sequelae}

\section{Richard L Whelan}

Associate Director of the Division of Surgical Oncology at NewYork-Presbyterian Hospital/Columbia University Medical Center, New York, NY, USA

Do meaningful immunologic differences exist between open and MIS methods in the setting of cancer? I defend the viewpoint that a measurable difference exists in the impact on immune function in favor of laparoscopic methods. However, from the outset, it is important that we broaden the discussion to include surgery-related blood protein alterations. Although some of these plasma compositional changes are likely to have an impact on immune function, which may in turn indirectly influence tumor growth or recurrence, others are not immune system-related at all. Instead, these "other" alterations may have an impact on angiogenesis, apoptosis, and tumor growth via other mechanisms. Furthermore, although not immune system related, these other sequelae may be of great importance. Perhaps another way to phrase the initial question is to ask how open and MIS methods influence the host's ability to fend off tumor recurrences and limit tumor growth after surgery. In addition, how does surgery influence tumor cells that remain in the host's bloodstream or tumor microfoci?

Findings show a growing list of parameters affected in different ways by open and closed surgical techniques. Harder than finding such parameters, however, is demonstrating that the physiologic, immunologic, and other host differences in response to surgery are important clinically. The most challenging task has been, and still is, to establish clinical relevance. In fact, in some cases, it is difficult even to determine whether a given change is "bad" or "good."

\section{Immunologic consequences of the surgical approach}

Before the laparoscopic era, it had been well established that major open surgery is associated with temporary suppression of a variety of cells involved with both innate and specific immunity including lymphocytes, neutrophils, monocytes, and macrophages. In addition, interactions between cells and other cellular functions are negatively influenced by open surgical trauma. Furthermore, the ability to mount a positive response to a DTH recall antigen challenge is suppressed after surgery [11-15].

The relative contribution of each part of an abdominal procedure (abdominal wall access incision vs. intraabdominal dissection and resection) to the postsurgical immunosuppression had not been assessed before the advent of advanced laparoscopic methods. The results of recent studies suggest that the method of entry into the abdomen is an important determinant of postoperative immune function.

For a variety of immune parameters, minimally invasive methods are shown to be associated with a significantly better preserved function than equivalent open procedures. Notably, in many cases, the differences are small and short lived, on the order of a day and sometimes less, for several variables. For a number of parameters, no differences have been noted.

DTH testing One of the simplest methods for evaluating immune function is DTH testing. The ability to mount a DTH response to an intradermally injected antigen the subject has previously encountered verifies that several important elements of the immune system are functioning, namely, antigen presentation, proliferation of the memory CD4 lymphocyte, cytokine elaboration, and the effector response, which results in the wheal at the injection site. By administering a series of DTH challenges, one before (establishing the baseline response) and several after surgery (compared with the preoperative result), it is possible to assess the functional state of the immune system.

Animal studies have shown that laparoscopic cecectomy is associated with significantly better preserved DTH responses than its open equivalent [16]. A small human nonrandomized DTH study was conducted with colectomy patients in the late 1990s. In this study, serial DTH challenges were given before and after surgery to both open and closed colorectal resection patients. The study demonstrated that open colectomy was associated with a significant decrease in the size of the mean DTH response when patients were challenged on the day of surgery and postoperative day (POD) 3, whereas the postsurgery responses of the minimally invasive colectomy group were not significantly smaller than their preoperative results [17]. A recently completed randomized human study that assessed the impact of perioperative granulocyte-macrophage colony-stimulating activity (GM-CSF) in the setting of minimally invasive colorectal cancer surgery has confirmed that there is no significant decrease in DTH response to tetanus or Candida on PODs 1 and 3 after 
minimally invasive colorectal resection (control group results) [18].

Cytokines Surgical trauma evokes a potent local and systemic inflammatory response manifested by rapid changes in the plasma concentration of various acute phase proteins and proinflammatory cytokines. Although increased levels of cytokines and acute phase proteins reflect an inflammatory response, they do not directly correlate with the status of the immune system. Plasma levels of acute phase proteins such as C-reactive protein (CRP), the most widely measured marker of the acute phase response, and the proinflammatory cytokines IL- $1 \beta$, IL-6, IL-8, and tumor necrosis factor- $\alpha$ (TNF $\alpha)$ typically are transiently increased after significant tissue injury. Interleukin-6, the best studied cytokine, has consistently been found transiently increased in response to injury.

Pre- and postoperative plasma levels of all the aforementioned inflammatory mediators have been compared in patients undergoing laparoscopic and conventional surgery. Most reports on the stress response after open and laparoscopic surgery have shown that open cholecystectomy is associated with higher postoperative plasma levels of CRP, $\mathrm{TNF} \alpha$, IL- $1 \beta$, and/or IL-6 relative to laparoscopic cholecystectomy, suggesting that open surgery is associated with a greater inflammatory response [19-23]. Significantly higher levels of some or all of these proteins also were found postoperatively in patients after conventional Nissen fundoplication $[24,25]$ and colorectal cancer resection than in patients undergoing laparoscopic surgery [26-30]. Other studies have shown that although both open and laparoscopic colorectal surgery are associated with elevated plasma CRP levels, these levels return more promptly to baseline preoperative values after laparoscopic than after open surgery [31].

Specifically with regard to IL-6 levels, conflicting results have been reported, although the discrepancy between various studies may be the result of differences in the sampling times. Investigators measuring IL-6 levels in the first $24 \mathrm{~h}$ after surgery have almost always found significantly higher levels in open surgery patients [27, 3234]. However, in a number of studies, the differences between open and closed colectomy patients were lost within $24 \mathrm{~h}$. Several of the studies reporting no difference between groups did not obtain the first sample until at least $24 \mathrm{~h}$ after surgery [35].

Lymphocytes Studies assessing the number of circulating lymphocytes of different subtypes have, with rare exception, found no significant differences between open and closed groups [31]. A randomized cholecystectomy study that indirectly assessed the ratio of Th-1 to Th-2 lymphocytes by measuring levels of interferon $\gamma$ (Th-1) and IL-4
(Th-2) elaborated by peripheral blood monocytes in vitro after stimulation found a significant difference between the laparoscopic and open groups only $2 \mathrm{~h}$ after the operation. All other sampling points yielded similar results between groups [36].

A recent colectomy study analyzed CD31 expression on circulating $\mathrm{T}$ lymphocytes before and after surgery. Efficient killing of tumor cells or other pathogens depends, among other things, on T-cell migration from the circulation to peripheral tissues. T-cells migrating from the circulation to the peripheral tissues express the CD31 antigen. In the open group, CD31 expression was found to be significantly decreased from preoperative baseline levels on the PODs 1 and 3. This was not the case in the laparoscopic group. Furthermore, a significant correlation was found between the decrease in CD31 expression and the incision length in the open group [37].

Some insight into the specific molecular effects of laparotomy and laparoscopy on T-cells comes from a microarray analysis on the time course of the differential effects of sham laparotomy versus $\mathrm{CO}_{2}$ pneumoperitoneum on splenic T-cell gene expression in mice [28]. Relative to anesthesia control, sham laparotomy $12 \mathrm{~h}$ after surgery resulted in notable alterations (differences in expression in 398 T-cell genes more than twofold compared with 116 genes after pneumoperitoneum). At $24 \mathrm{~h}$, the differences between the two surgical methods were less marked, with altered expression noted in 157 genes after laparotomy versus 132 genes after pneumoperitoneum.

When global gene expression was compared between laparotomy and pneumoperitoneum, the expression of 177 genes was increased after laparotomy relative to pneumoperitoneum at $12 \mathrm{~h}$, a difference reduced fourfold at the 24$\mathrm{h}$ time point [38]. Functional differences in gene expression 12 to $24 \mathrm{~h}$ after surgery also were noted in both groups. These transient but substantial alterations in splenic T-cell gene expression profiles after laparotomy provide a molecular basis for the observation that open surgery is associated with transient but marked immune alterations. Ongoing functional analysis of those genes with differential expression in response to laparotomy and pneumoperitoneum not only will uncover the biologic significance of these differences, but also may identify genes that can be used as clinical markers of the effect surgery has on the immune system.

Monocytes and macrophages Results regarding the in vitro function of circulating monocytes and peritoneal macrophages conflict and are difficult to interpret. According to some studies, $\mathrm{CO}_{2}$ pneumoperitoneum may inhibit or downregulate peritoneal macrophage function. However, in a rodent study comparing open and closed cecectomy in the author's lab demonstrated that open 
surgery is associated with significantly lower $\mathrm{H}_{2} \mathrm{O}_{2}$ release (a reflection of respiratory burst activity) from peritoneal monocytes on POD 1 compared with anesthesia control results. These results suggest that the peritoneal macrophages are less ready and able to function after open surgery [39].

In a pig study that compared open and closed Nissen fundoplication, Collet et al. [40] assessed the ability of the peritoneal cavity to clear $10^{9}$ Escherichia coli introduced into the abdomen at the end of the operation. Bacterial counts of peritoneal fluid samples were taken 1,2 , and $8 \mathrm{~h}$ after surgery. The open group bacterial count was dramatically higher than that of the closed group count $8 \mathrm{~h}$ after the operation. However, the assessment in vitro after recovery showed no differences in the ability of peritoneal or circulating monocytes to phagocytize Staphylococcus aureus between the open and closed groups.

A recently published large animal study of peritoneal macrophages compared the impact of open, hand-assisted, and laparoscopic nephrectomy on macrophage IL-6 and TNF production [41]. Peritoneal macrophages were harvested 4,12 , and $24 \mathrm{~h}$ after surgery. These peritoneal macrophages were cultured and then stimulated with lipopolysaccharide, after which the levels of the aforementioned cytokines were determined. All three types of surgery were associated with increased TNF and IL-6 levels. However, the open nephrectomy group results at the 12- and 24-h time points were significantly greater than the results of the hand and laparoscopic groups, whose results were similar [42]. These results imply that open methods are associated with peritoneal macrophage activation to a greater extent than MIS methods.

As the aforementioned three studies show, the literature is conflicting with regard to peritoneal macrophages. Thus, it is not clear what the "take-home" message is with regard to peritoneal macrophages. Similarly, the clinical relevance of these results, if any exists, is unknown.

With regard to peripheral blood mononuclear cells (PBMCs), a randomized study of human colectomy patients demonstrated a small but significant difference in expression of the human leukocyte antigen marker (HLADR) on circulating monocytes in favor of the laparoscopic patients on the POD 4 [27]. This is an activation marker for monocytes. Decreased expression rates have been associated with a worse outcome for trauma patients.

Clinical import It should be realized that the clinical significance of the immune function differences, if any exists, has not been determined. Better preserved postoperative cell-mediated immune function, in theory, may have an impact on the rate of infections and possibly tumor recurrence and survival rates. The low rate of port-site wound infections noted for most laparoscopic procedures and the significantly better disease-free survival of laparoscopic patients after colectomy for cancer noted by Lacy et al. [43] in their randomized study seem to support this notion.

Etiology of surgery-related immunosuppression What is it about abdominal surgery that causes temporary suppression of the immune system? Probably a number of contributing factors are involved. Evidence shows that the overall length of an abdominal wall incision is an important factor. Some authors, considering the results of a murine study, believe that the exposure of the abdominal cavity to air is the cause of the immunosuppression after open surgery. These latter investigators believe that small amounts of lipopolysaccharide in the air cause immunosuppression by stimulating bacteria in the intestine to elaborate lipopolysaccharide, which then translocates across the bowel wall, after which it is absorbed systemically [44].

Possible future immunotherapies The controversy surrounding laparoscopic surgery for cancer has led to studies that have significantly increased our understanding of surgery's impact on the body. This will hopefully lead to new perioperative pharmacologic therapies that will lessen the deleterious immunologic effects of all types of surgery. This type of approach is exemplified by administration of immunostimulatory agents perioperatively to cancer patients. Small animal studies have shown that such treatment is associated with significantly lower tumor recurrence and metastases rates [45, 46]. Mels et al. [47] in a small randomized trial of 16 open surgery patients demonstrated that seven perioperative doses of GM-CSF was associated with significantly better preserved postoperative DTH responses and HLA-DR expression on monocytes than placebo. Usually, GM-CSF is used as a bone marrow rescue agent in chemotherapy patients.

A similar randomized human study of perioperative immunomodulation in the setting of colorectal cancer has just been completed at Columbia University with a total of 59 patients [18]. In this study, GM-CSF was given daily three times before surgery and then for the first 4 postoperative days to patients undergoing MIS. The goal was to upregulate immune function perioperatively and also to determine the impact of this treatment. The drug was well tolerated and not associated with any discernible complications. Unlike the Mels et al. [47] study mentioned earlier, the Columbia study did not demonstrate significantly better immune function after GM-CSF treatment, as measured by serial DTH responses, number of DR + monocytes, array of Th1/Th2 cytokines, or plasma IFN- $\gamma$ levels.

One possible reason for these findings is that it may have been much harder to demonstrate immune benefits for the GM-CSF group because the immune function of the control 
patients (all laparoscopic patients) was better preserved than in the open surgery control group of the Mels et al. [47] study, which demonstrated more dramatic decreases in the immune parameters followed. An unexpected and noteworthy finding of this GM-CSF study was its clear demonstration that GM-CSF results in significantly higher soluble vascular endothelial growth factor (VEGF)-receptor 1 levels and a significantly higher angiopoetin 1/angiopoetin 2 ratio on POD 5 than in the control group. Furthermore, findings showed that post-GM-CSF blood on POD 5 significantly decreased endothelial cell proliferation and invasion in in vitro cultures. These results suggest that angiogenesis is inhibited by GM-CSF [18].

Another possible immunotherapy would be administration of preoperative tumor vaccines to encourage the development of an active immune response against the tumor before resection. Then, in the early postoperative period, when the tumor burden is at its lowest, the patient would have a means of eliminating any viable tumor cells that may remain. In small animal studies, this approach has been successful in lowering the rate of metastases [47]. To the author's knowledge, no human preoperative vaccine trials are underway currently.

\section{Surgery-related protein alterations}

Not surprisingly, surgery has an impact on the composition of plasma, which contains a countless number of different proteins. Because the bloodstream is "downstream" of all the body's organs, it is difficult to determine the source or sources of the protein changes detected in the plasma or serum. Furthermore, although some in vitro data assess the impact of surgery-related plasma protein alterations, it generally is difficult to determine the clinical significance of many documented alterations. Whereas the function and effects of most of the proteins assessed have been well studied in vitro and, in some cases, in vivo, few data exist regarding the import of temporary and sometimes modest changes in the plasma levels of these parameters. Also, the precancer resection plasma levels of some parameters (VEGF is a prime example) are shown to be significantly higher in cancer patients than in control patients without tumors. High blood VEGF levels correlate with advanced disease stage and a worse prognosis. Plasma VEGF levels increase after open and closed colorectal resections and remain increased for at least 3 weeks (see later) [48].

Despite this very interesting finding, it has not been established that this sustained increase has any bearing on the oncologic outcome. Thus, similar to the situation with the immune parameters, the burden of proof remains with the laparoscopic enthusiasts to demonstrate clinical outcome benefits for the closed patients. The blood protein alterations that may have an impact on tumor growth are emphasized in this brief review.

\section{Insulin-like growth factor-binding protein}

Perhaps the best evidence, albeit in vitro data, regards insulin-like growth factor binding protein-3 (IGFBP-3). This well-studied protein has been shown to inhibit tumor growth via several mechanisms. Besides binding and essentially "tying up" insulin-like growth factor (IGF)-1, a major cell growth factor (an indirect effect), IGFBP-3 also induces apoptosis in most tumor cell lines. This protein also inhibits DNA synthesis in poorly differentiated cell lines. Thus, IGFBP-3 is an endogenous inhibitor of tumor growth. At baseline, the vast majority of people have fairly high levels of this protein. Notably, only the intact protein has the tumor inhibitory effect. In contrast, the partially degraded IGFBP-3 protein does not have this effect.

Major abdominal surgery, in open more than in laparoscopic surgery, is associated with a 1-3-day significant decrease in plasma levels of intact IGFBP-3 [49]. In the laparoscopic patients, a nonsignificant decrease was observed. The duration of the larger decrease in the open surgery patients was associated with the incision length.

Furthermore, POD 1 plasma (with decreased intact IGFBP-3 levels) from open colectomy patients has been shown to stimulate in vitro tumor cell growth compared with culture results obtained when preoperative plasma from the same patients is assessed. The fact that when exogenous IGFBP-3 is added to the postoperative plasma no increase in the in vitro tumor growth rate over baseline is observed suggests that the decrease in IGFBP-3 levels is responsible for the tumor growth stimulation noted with the "raw" postoperative plasma [50].

\section{Matrix metalloproteinase-9}

Several of the matrix metalloproteinases (MMPs) are thought to play an important role in tumor growth and spread. Findings have shown plasma MMP levels to be elevated in patients with a variety of different cancers. These proteolytic enzymes are capable of degrading connective tissue at the border of tumors, thus permitting the spread and growth of the tumor in question. In the plasma, MMP-9 has been demonstrated to degrade IGFBP-3 and is thought to be the mechanism by which open surgery results in a decrease in IGFBP-3 levels.

In a study of 88 open and closed colorectal cancer patients, a significant increase in plasma MMP-9 levels was noted on POD 1 in the open group, whereas no sizable change in the laparoscopic group's levels occurred. The decrease in MMP-9 levels is very transient, and by PODs 2 and 3, the levels have returned to normal [51]. 


\section{Tissue inhibitor of metalloproteinase-1}

The most likely reason why the preceding noted MMP-9 decrease is so short lived is that plasma tissue inhibitor of metalloproteinase-1 (TIMP-1) level also rises after open surgery and remains significantly elevated over baseline for at least the first 3 days after surgery. Laparoscopic patients manifest a smaller yet still significantly increased TIMP-1 level after surgery [51].

Similar to the situation with the MMPs, findings have shown TIMP-1 levels to be elevated in the setting of several different cancers. The clinical import of these transient increases is uncertain.

\section{VEGF}

As a potent inducer of angiogenesis, VEGF is critical for wound healing and plays a crucial role in the early steps of angiogenesis. It is logical to anticipate that plasma levels increase after major surgery. In addition, VEGF has been shown to facilitate and promote tumor growth. Findings have demonstrated that many tumors, including colonic adenocarcinoma, cannot grow beyond 2 to $3 \mathrm{~mm}$ without the development of new blood vessels.

When groups of cancer patients have been evaluated before resection, findings have shown their mean serum and plasma VEGF levels to be significantly higher than the mean levels of control populations without tumors [52-54]. The height of the elevation for some tumors, including the colon, correlates with the stage of disease or prognosis in some series.

What impact does surgery have on blood VEGF levels? A postoperative increase in plasma VEGF levels may facilitate tumor growth early after surgery. In a study published in the fall of 2008, early postoperative plasma VEGF levels were studied in the setting of both open and minimally invasive colorectal resection for cancer and for benign indications. In the open cancer patients, a significant and stepwise increase was noted on PODs 1 and 3 compared with preoperative levels. In the laparoscopic patients on POD 3, a significant VEGF increase over baseline value also was noted. Notably, however, the mean laparoscopic value, although increased, was significantly lower than that noted in the open group at the same time point. Also, no increase was noted on POD 1 in the closed group. Although the benign colorectal resection patients' baseline VEGF levels were lower than those of the cancer group, their response to surgery was very similar, showing a steady increase in the open group and a delayed and blunted increase in the laparoscopic group.

A more recent study assessed plasma VEGF levels during the first postoperative month after laparoscopic colorectal resection for benign (30 patients) and malignant
(49 patients) disease. In the cancer patients, VEGF levels continued to rise, peaking during postoperative week 3 . Significant elevations were noted from POD 3 through postoperative week 4 . Similar yet lower and less persistent elevations were noted in the patients with benign disease (values peaked during the second week) [48]. To the author's knowledge, this is the first surgery-related plasma protein alteration to date demonstrated to persist for this length of time. Given the fact that these were minimally invasive patients, the findings came somewhat as a surprise. Whether levels for open colorectal resection patients would be similar remains to be shown. In the author's view, although it is possible that open surgery patients will manifest even greater plasma VEGF elevations, it is more likely that these patients will demonstrate similar elevations. Thus, the transient 1-2-day delay in VEGF increase observed after closed surgery may be of little significance considering the long duration of the effect.

\section{Angiopoetin 1 (Ang 1) and angiopetin 2 (Ang 2)}

These proteins play important yet conflicting roles with regard to VEGF-mediated angiogenesis. Both bind to the Tie-2 receptor. Whereas Ang 1 stabilizes mature vessels and inhibits VEGF-mediated angiogenesis, Ang 2 is thought to encourage and promote VEGF-mediated angiogenesis. The ratio of plasma Ang 1 to Ang 2 levels is thought to be a measure of the body's tendency toward VEGF-mediated angiogenesis. A high ratio would encourage blood vessel stabilization, whereas a low ratio would favor the VEGF-stimulation effects that stimulate new vessel formation.

A study investigating the benign pathology of open and closed colon and rectal resection patients demonstrated that both surgical methods are associated with a decrease in Ang 1 and an increase in Ang 2 levels on PODs 1 and 3 such that a significantly greater Ang 1/Ang 2 ratio was noted at both time points. The magnitude of the Ang 2 and Ang 1/Ang 2 ratio changes was significantly greater in the open resection group [55].

A recently completed study of more than 100 colorectal resection patients demonstrated that after either open or minimally invasive resection (on both PODs 1 and 3), Ang 1 levels were significantly lower and Ang 2 levels significantly higher compared with the preoperative results for both benign and cancer indications. Similarly, the Ang 1/ Ang 2 ratio on PODs 1 and 3 after both types of surgery was significantly lower, favoring VEGF-mediated angiogenesis. Although both surgical methods had similar effects on Ang 1, Ang 2, and the Ang 1/Ang 2 ratio, the extent of the changes (decrease in Ang 1, increase in Ang 2 , and decrease in the Ang 1/ Ang 2 ratio) was significantly greater after open colorectal resection. Thus, surgery in 
general results in similar effects. However, open surgery has a notably greater impact [56].

\section{Summary of studies}

Clearly, MIS is associated with fewer marked perturbations of the immune system. It makes sense that it is desirable to maintain baseline immune function and status. Thus, laparoscopic surgery is preferable to open methods from this vantage point. Better clinical data are needed with regard to short- or long-term outcome measures that demonstrate advantages for the MIS patients. Lower wound infection and morbidity rates have been reported by some investigators. These may be the clinical reflection of better preserved immune function. The shorter hospital stay also may be related in some way. However, this has not been proved and would be hard to demonstrate.

\section{The controversy: does MIS surgery have advantages for the perioperative management of cancer patients?}

Pro: Perioperative complications and length of hospital stay are reduced with MIS cancer surgery

\section{Christopher Schlachta}

Associate Professor of Surgery and Oncology, Schulich School of Medicine and Dentistry, Ontario, Canada

It has been nearly a quarter century since Karl Semm performed the first laparoscopic appendectomy and 20 years since Muhe and Mouret heralded the modern era of MIS. The early promise of smaller scars, less pain, fewer complications, and shorter hospital stay that accompanied the introduction of laparoscopic cholecystectomy led to nearly every operation in the abdominal cavity being described in some laparoscopic fashion (and currently with robotics). The benefits of the laparoscopic approach seem to vary according to the type of procedure, with some procedures showing clear advantages over open surgery, and others showing more moderate improvements.

One thing is clear. Minimally invasive surgery directly and indirectly changed the way we think about surgery and the way we care for our surgical patients. This latter point may lead to the most indisputable argument supporting this resolution. When perioperative complications that may be avoided by laparoscopy were considered, the natural early inclination was to study pulmonary function and recovery. Evidence from randomized trials of open versus laparoscopic cholecystectomy have clearly demonstrated less impairment and more rapid recovery of pulmonary function after the laparoscopic approach. This has been replicated with other surgeries including colon surgery. However, because perioperative pulmonary complications are fairly infrequent, most trials have been underpowered and unable to detect a significant advantage for laparoscopy.

One clear advantage of MIS is the smaller scars that result. Many have paternalistically dismissed the cosmetic advantages of smaller scars but have overlooked the very significant impact that small scars have on postoperative wound complications. Several procedures including laparoscopic appendectomy [57], colectomy [58-60], and gastric bypass [61] boast level 1 evidence of reduced wound infections with laparoscopy. Findings have further shown that laparoscopic gastric bypass [61] and colectomy [62] are associated with a lower incidence of incisional hernia formation. The latter study from the Cleveland Clinic, albeit retrospectively, also found a significant reduction in hospital readmission for small bowel obstruction with laparoscopy and a $51 \%$ reduction in the requirement of reoperation for these two complications. To compound this issue further, one study found fewer postoperative wound complications associated with laparoscopic repair of ventral hernias, presumably arising from prior open surgery [63].

Perhaps most compelling is the recent metaanalysis investigating trials of laparoscopic versus open colectomy by Tjandra and Chan [60]. This metaanalysis reported on 17 prospective randomized clinical trials involving more than 4,000 procedures. It found a reduction in perioperative mortality associated with laparoscopy.

The overall length of hospital stay is the other closely scrutinized advantage of laparoscopic surgery. Once again, the benefits are clear with some procedures such as laparoscopic cholecystectomy [64], bariatric surgery [61], and antireflux surgery [65]. The gains with laparoscopic colectomy have been more moderate, leading some to question the magnitude of this advantage. Three metaanalyses investigating prospective randomized trials of laparoscopic versus open colon surgery all conclude that the highest-level evidence shows laparoscopic colon surgery to be comparable with open surgery, leading to a significant reduction in postoperative hospital stay [58-60].

It might then be asked why any debate exists regarding the clear advantage of laparoscopic surgery in terms of hospital length of stay. This debate arises from the expanding body of work surrounding "fast-track" surgery. It is clear that by modifying the perioperative care we deliver to our patients, by minimizing pain and other factors that incite the surgical stress response, and by releasing our patients from the shackles of unnecessary tubes and drains, we can mitigate the trauma of surgery and reduce the need for hospitalization. Laparoscopic surgery is just one very effective component of this multimodal care, and patients having laparoscopic procedures also can benefit from these interventions. 
The only suggestion that the advantages of laparoscopy have been supplanted by "fast-track" protocols has come from one randomized trial of 60 patients who underwent laparoscopic and open colon surgery. It was reported that the median lengths of hospital stay between the two groups were not significantly different [66]. Although this was clearly a provocative effort and the only truly doubleblinded trial conducted to date, a number of methodologic concerns surround the design and analysis of this trial that call significantly into question the validity of its findings. There also was a high hospital readmission rate (29\%). Most important, despite assurances that discharge criteria were the same between groups and that patients, nurses, and physicians were blinded to the type of operative procedure, nurses still were able to guess which patients had undergone laparoscopy, and both patients and their relatives in the open surgery group were more likely to feel they were pushed out of the hospital too quickly. This alone suggests that no amount of fast tracking is going to invalidate the advantages of laparoscopy.

The final point that comes to fore is simply this: no one ever cared about the length of hospital stay before MIS threatened the status quo. That we are even debating the advantages of laparoscopy in light of recent efforts in "fast-track" care is solid proof of the indisputable effect laparoscopic surgery has on reducing the length of hospital stay.

Con: Perioperative complications and length of hospital stay are equivalent for open and MIS cancer

\section{Richard P. Billingham}

Clinical Professor, Department of Surgery, University of Washington, Seattle, Washington

Is laparoscopic surgery, in fact, good enough to replace open surgery? Are current laparoscopic techniques as good as it is going to get? Does the size of the incision really matter? These were some of the fundamental questions debated in the surgical literature as laparoscopic surgery became not only a reality but also an option more frequently demanded by patients.

As an example, advantages quoted for laparoscopic colectomy include less pain, earlier resumption of GI function, shorter hospital stay, fewer complications, less interference with immune functions, and the fact that it is "feasible and safe." It also is said that because of these advantages, "the public demands it." Recent figures for length of hospital stay in papers published over the past 12 months are 5 to 8 days after laparoscopic colectomy. It is rare to find a quoted hospital stay shorter than 4 days, which is the commonly quoted length of stay for open surgery if critical pathways are used. Interestingly, when length of hospital stay figures are quoted for laparoscopic colectomy patients, these patients typically have been treated differently from open colectomy patients in the same study, and the two groups have not been subjected to a similar "critical pathway" or "fast track."

An important paper from Basse [66] appearing in March 2005 reported a randomized blinded trial of 60 patients older than 55 years. All these patients had elective right or sigmoid resections, epidural anesthesia, and anastomoses more than $12 \mathrm{~cm}$ from the anus, but patients and observers were both blinded to the type of surgery used for each patient. This meant that the physicians making their rounds for the patient after surgery were not the ones to inspect the incision and were not privy to information about whether the patient had laparoscopic or open colectomy. In this study, the operative time was about 50\% longer for the laparoscopic surgery, but importantly, patients with an open procedure had a shorter hospital stay (2.3 vs. 2.9 days). In addition, the laparoscopic patients had a higher pain score than those undergoing open surgery. No difference was found in GI function, cardiopulmonary function, mental function, CRP levels, convalescence, or patient satisfaction.

Similar trials and results were found by King et al. [67] from the United Kingdom in March 2006 and by MacKay et al. [68], with essentially no difference in mean hospital stay between the laparoscopic and open groups. The shortest hospital stay reported in the paper by King was 5.2 days, which is comparable with that seen using critical pathways for open surgery in the United States.

Postoperative complications and outcomes have been compared in many papers. The metaanalysis of Abraham et al. [59] published in 2004 that included 2,512 patients from 12 randomized control studies showed no significant reduction in overall morbidity rate with laparoscopic versus open surgery. The only difference found in local complications was that wound infection rates were twice as high for open versus laparoscopic cases, but these studies were uncontrolled for the use of wound protectors and 34 other factors known to reduce the incidence of wound infection.

In the MRC CLASICC trial 5 reported in May 2005, mortality after open surgery was reported to be $5 \%$ compared with only $1 \%$ after laparoscopic surgery [69]. However, in this study, 29 patients required conversion, and the mortality rate for the patients in this group was $9 \%$, even higher than had the patient undergone open surgery initially. In this study, no differences were found in terms of intraoperative complications, 30- or 90-day postoperative complications, 7-day transfusion requirements, or quality-of-life scores. Interestingly, the authors stated that "impaired short-term outcomes after laparoscopic-assisted anterior resection for cancer of the rectum do not yet justify its routine use." In the COLOR trial reported in 2005 [70], no difference was noted in terms of morbidity or mortality, 
but again, this trial was not controlled for perioperative care.

The most recent metaanalysis, published by Noel et al. [71] in February 2007 found 88 comparisons of MIS with open surgery. These authors narrowed this down to what they believed were more comparable trials. Only 22 of these studies were, in fact, randomized controlled trials. No difference was seen in terms of perioperative mortality, and with perioperative morbidity, the wound infection rate was $2.9 \%$ for the laparoscopic cases compared with $4.4 \%$ for the open cases. The open group showed a slightly higher incidence of respiratory problems $(1.0 \%$ vs. $1.6 \%)$, but no other significant differences. The mean length of hospital stay after laparoscopic surgery in these groups was 7.8 days compared with 11.6 days for open surgery. However, again, none of the studies was controlled for perioperative care.

Another review, published in August 2006 by Reza et al. [72] also found no significant differences in the incidence of complications or postoperative mortality, but did observe that the time required for laparoscopic colectomy was significantly longer. These authors also noted no significant differences in overall mortality, cancer-related mortality, or disease recurrence.

Conversions remain an ongoing problem, and rates typically are in the $15 \%$ range. A consequence of conversion is that morbidity and mortality are greater in the converted group than for patients who undergo open surgery initially. Marusch et al. [73] in 2001 found appreciably poorer results after conversion, and Senagore et al. [74] in 2003 noted that the average length of hospital stay triples for patients who have undergone conversion. In the study by Moloo et al. [75] in May 2004, 11 converted patients had a $12 \%$ absolute decrease in survival at 2 years and a $7.8 \%$ absolute decrease in survival at 5 years.

The advantages of open colectomy include versatility, speed, efficiency, a shorter learning curve, lower cost, and greater safety. The disadvantages of open colectomy would seem to be immunologic indicators, although the significance of the findings in this field is completely unknown. Certainly, no difference is found between open and laparoscopic surgery in duration of postoperative ileus, time until resumption of oral feeding, or length of hospital stay when critical pathways are used. There may be a slight increase $(1 \%)$ in the wound infection rate, but with modern methods of treating wound infections, this generally does not involve any additional hospital stay or expense.

In November 2005, Dr. Robin Macleod [76] noted that from a Canadian perspective, cancer results are similar. No difference is found in quality of life, pain, or discharge times, and there are significant concerns about costs and training. In September 2006, Cecil et al. [77] noted a high rate of anastomotic leakage with laparoscopic surgery, quoting papers by Morino et al. [78] in 2003 and Leroy et al. [79] in 2004, both of which showed anastomotic leak rates in the $20 \%$ to $25 \%$ range, concluding that all laparoscopic rectal cancers should be defunctioned. These authors also note that "one of the main advantages of laparoscopic colorectal surgery, namely, earlier mobilization and discharge, has been difficult to demonstrate with laparoscopic rectal resection." In Dr. Rattner's [80] presidential address for SAGES in April 2005, he states: "We must move beyond laparoscopic surgery if we are to remain relevant."

In summary, open colectomy still is preferred in most cases because of its versatility, speed, efficiency, shorter learning curve, less morbidity, greater safety, and lower cost. It is highly questionable whether the difference in incision size makes any clinical difference, and it probably is more important to know what to do than to debate about whether to perform it with open or laparoscopic procedure or how long the incision should be. The reasons for avoiding laparoscopic colon surgery are that it offers increased cost but minimal or no advantage to the patient, either oncologically, in terms of perioperative care, or for quality of life.

\section{The controversy: what is the role of perioperative staging for esophageal and gastric cancer?}

Pro: Endoscopic ultrasound and MIS staging play an integral role in the management of primary esophageal and gastric cancer

\section{Jeffrey Ponsky}

Professor and Chairman in the Department of Surgery at Case Western Reserve University School of Medicine, Cleveland, $\mathrm{OH}$

In Western countries, esophageal and gastric cancers have been increasing in incidence and prevalence over several decades. Both cancers generally have a poor prognosis. The 5-year survival rate for esophageal cancer approximates $15 \%$, and the overall 5-year survival rate for gastric cancer is $15 \%$ to $20 \%$, although up to $60 \%$ of patients with localized lesions have long-term survival.

Staging plays two integral roles in the management of esophageal and gastric cancer: to detect potentially curable patients and to avoid nontherapeutic laparotomy for those who have incurable disease [81]. Standard staging methods for esophageal and gastric cancer include computed tomography (CT) and positron emission tomography (PET) scans. Both are accurate in detecting gross metastatic disease but may miss subtle lymph node metastases. Furthermore, standard imaging cannot adequately assess tumor (T) stage in the tumor node metastasis (TNM) classification [82]. To that end, endoscopic ultrasound (EUS) and MIS 
(thoracoscopy and laparoscopy) have been instituted for accurate staging of esophageal and gastric cancers. Both EUS and MIS are vital components of staging, directing appropriate therapy to patients with gastric or esophageal cancer.

\section{EUS in esophageal cancer}

In esophageal cancer, T1-T3 lesions are considered operable and resectable. In esophageal cancer, EUS is the most accurate means of determining T-stage [83]. Endoscopic ultrasound displays five distinct layers of the esophageal wall, namely, the echo/superficial mucosa boundary, the mucosa, the submucosa, the muscularis propria, and the adventitia. As shown by pathology specimens, the sensitivity of EUS for T-staging is $85 \%$ to $90 \%$, far exceeding that of other available imaging methods.

Patients with advanced locoregional disease may benefit from neoadjuvant therapy before surgery. Endoscopic ultrasound has the capability to detect regional lymphadenopathy and to sample suspicious lymph nodes by fineneedle aspiration. The characteristics of suspicious lymph nodes include size larger than 8 to $10 \mathrm{~mm}$, sharp demarcation from the surrounding fat, hypoechoic density, and rounded shape. The sensitivity of EUS in detecting lymph node involvement compared with pathology is approximately $70 \%$ [82]. The diminution in sensitivity results from the difficulty in deciphering benign from malignant adenopathy and sampling errors from fine-needle aspiration.

Involvement of the celiac nodes in esophageal cancer is considered to be metastatic disease. Endoscopic ultrasound is the most accurate method for evaluating the celiac lymph nodes. Moreover, EUS may add prognostic value for patients receiving neoadjuvant therapy by assessing the local response after treatment [84].

\section{EUS in gastric cancer}

Endoscopic ultrasound displays a resolution of $0.1 \mathrm{~mm}$ when imaging the gastric wall. Therefore, EUS is highly accurate in determining T-stage in early gastric cancers. Gastric EUS shows five hypoechoic levels with corresponding histologic layers: the water-superficial mucosa barrier, the deep mucosa, the submucosa, the muscularis propria, and the serosa and subserosal fat. The use of a high-frequency probe $(20 \mathrm{MHz})$ may improve detection of early tumors, whereas a low-frequency probe $(7.5 \mathrm{MHz})$ allows better visualization of advanced tumors [85]. Tumors confined to the first three EUS layers are considered T1 lesions. For such lesions, EUS has shown accuracy up to $100 \%$. Overall accuracy for T-staging is $80 \%$, and more advanced tumors obscure echoendoscopic images because of accompanying fibrosis and inflammation [82].
Assessing regional lymph node involvement is possible with EUS. The accuracy of nodal staging is $60 \%$ to $65 \%$, with higher accuracy achieved when fine-needle aspiration is implemented. Although often technically challenging, EUS interrogation for regional lymphadenopathy provides important prognostic information.

Endoscopic ultrasound also offers the capability for assessing metastatic disease in gastric cancer. Most of the liver's left lobe can be evaluated with the EUS probe positioned near the esophagogastric junction. Moving the probe to the distal stomach and bulb of the duodenum permits visualization of part of the liver's right lobe. In one study, EUS was able to detect unsuspected liver metastases (i.e., those that evaded CT detection) in $7 \%$ of gastric cancer patients [86].

\section{MIS for esophageal cancer}

Thoracoscopy and laparoscopy are considered complements to standard staging for select patients with esophageal cancer. Thoracoscopy through the right hemithorax allows visualization of the upper two-thirds of the thoracic esophagus and aortopulmonary nodes, whereas the lower esophagus is investigated through the left chest.

Nodes can be sampled thoracoscopically using standard techniques. These techniques have shown accuracy for lymph node involvement ranging from $80 \%$ to $95 \%$, as shown by pathology specimens. Due to the lack of sensitivity of EUS, CT, and PET, MIS techniques may change staging in up to $40 \%$ of patients with esophageal cancer.

Laparoscopy may have utility for patients with cancers of the esophagogastric junction. Using a three-port technique, the entire peritoneum can be searched for implants, the lesser sac can be entered for examination of the celiac nodes, and the liver can be inspected [87]. Additionally, feeding jejunostomies can be placed using laparoscopic techniques in patients found to harbor metastatic disease.

Laparoscopy is recommended for patients with advanced stages of esophageal cancer detected by conventional imaging. Thoracoscopy should be used selectively for patients with lesions in the mid esophagus.

\section{MIS for gastric cancer}

For staging gastric cancer, CT scanning has a sensitivity considerably less then $100 \%$. Patients with small-volume metastatic disease have life expectancies of 6 to 9 months. To spare nontherapeutic laparotomies, laparoscopic staging is indicated for surgical candidates with locally advanced disease but no evidence of metastases [87].

Laparoscopic staging is not needed for T1 lesions because they should go directly to definitive operation. An extensive laparoscopic examination is performed in the 
staging of gastric cancer. The entire peritoneum is examined. The surface of both the right and left liver lobes is inspected. The root of the mesentery is examined for local invasion. The lesser sac is entered for visualization of the celiac plexus and the caudate lobes of the liver.

Laparoscopic staging in gastric cancer detects CT-occult metastatic disease in up to $40 \%$ of patients. Irrigation of the peritoneum, with cytologic examination of the aspirate, may increase the detection of metastatic disease. In most studies, laparoscopic staging spares nontherapeutic laparotomy for one-third of gastric cancer patients. Less then $10 \%$ of these patients subsequently require laparotomy for palliative measures.

\section{Conclusion}

Both EUS and MIS provide critical staging information in cases of esophageal and gastric cancer and serve to restrict nontherapeutic operations in patients with a limited life expectancy. Endoscopic ultrasound for esophageal cancer and laparoscopy for advanced gastric cancer should be considered standard, whereas EUS for gastric lesions and MIS for esophageal cancer should be applied for select patients.

Con: Preoperative staging may not alter the management of primary esophageal and gastric cancer

\section{Mitchell C. Posner}

Chief of the Section of General Surgery and Surgical Oncology at the University of Chicago

The management of esophageal and gastric cancer has evolved considerably over the past decade. Significant technological advances have been applied to the diagnosis and staging of both esophageal and gastric cancer. Emerging technologies in imaging and endoscopic/laparoscopic methods have substantially improved our ability to stage patients accurately before therapeutic interventions. Further refinements in staging are being explored currently as investigators apply techniques in molecular genetics that likely will provide a unique "fingerprint" for tailoring therapy to each individual patient. However, the most significant breakthroughs in the overall management of patients with esophageal and gastric cancer have involved the area of therapeutics, in which a "new" paradigm exists. This paradigm has at its core the explicit understanding that tumor biology, not staging, dictates treatment response and outcome.

The biology of esophageal cancer is best illustrated by the sobering fact that the number of deaths from esophageal cancer in the United States is nearly equivalent to the number of new cases diagnosed each year [88, 89]. Therefore, the concept of "early" esophageal cancer does not reflect reality for the population of patients treated in this country. Results from the National Cancer Data Base on esophageal cancer identify only $14 \%$ of patients receiving a diagnosis of stage 1 disease at presentation [90]. It is important to note that only $63 \%$ of patients classified as having "early" esophageal cancer will not experience recurrence within the first year from the start of treatment. Therefore, the term "early-stage esophageal carcinoma" is a misnomer because the vast majority of patients have either occult regional (lymph node) or distant disease at the time of presentation.

Overall 5-year survival rates have increased over the past three decades, from a low of $5 \%$ in the 1970 s to $15 \%$ in the 1990s [91]. This improvement, although modest at best, can to a great extent be attributed to the therapeutic paradigm shift toward neoadjuvant chemotherapy/ chemoradiotherapy.

A substantial body of evidence now exists to support the use of preoperative chemotherapy or chemoradiotherapy before resection. The results from prospective randomized trials demonstrate an improvement in survival favoring patients who receive preoperative therapy rather than surgery alone [92, 93]. Substantial downstaging has been observed regardless of the documented stage at presentation, and the survival of patients who do respond is substantially better than that of patients who do not respond. Recent reports of trials examining the role of PET scans to assess early metabolic response confirm that biologic behavior, not staging, may be the most important predictor of response to treatment and eventual outcome. Fluorodeoxyglucose (FDG)-PET imaging 2 weeks into the course of preoperative chemotherapy reliably predicts response to induction chemotherapy, correlates with improved survival, and for patients identified as nonresponders, allows for a treatment change in the form of an alternative chemotherapy regimen or surgical intervention [94, 95].

In summary, the overwhelming majority of patients with esophageal carcinoma present with advanced disease, whereas a substantial number of patients with "early"stage carcinoma of the esophagus harbor occult metastatic disease. In both instances, staging does not and should not alter the therapeutic approach demonstrated to improve outcome. Neoadjuvant chemotherapy/chemoradiotherapy effectively downstages both early and advanced tumors, and the biologic response, as measured by surrogates such as FDG-PET, may be more predictive of successful treatment than the extent of disease at the time of diagnosis.

As with esophageal cancer, the vast majority of patients with gastric adenocarcinoma have locally advanced disease at the time of their initial presentation. National Cancer Data Base results demonstrate that only $9 \%$ of patients present with stage 1a (T1, N0) disease [96]. The 5-year survival rate in the United States for stage 1a disease is only $78 \%$, with a substantial dropoff in 5-year survival for higher-stage disease: $58 \%$ for stage $1 \mathrm{~b}, 34 \%$ for stage 2 , 
$20 \%$ for stage $3 \mathrm{a}$, and $8 \%$ for stage $3 \mathrm{~b}$. The control arm (surgery alone) of a prospective randomized trial examining the value of perioperative chemotherapy in resectable gastroesophageal cancer confirms that a minority of patients $(8.3 \%)$ present with $\mathrm{T} 1$ gastric carcinoma [97, 98]. Preoperative staging would have value only if therapy was altered based on staging information. The results from this randomized trial (MAGIC) of perioperative chemotherapy versus surgery alone suggest that staging influences prognosis but not treatment.

The MAGIC trial demonstrates a significant improvement in both progression-free and overall survival favoring the patients who received perioperative chemotherapy for resectable carcinoma of the stomach, esophagogastric junction, or lower esophagus [89]. Patients randomized to the perioperative chemotherapy arm of the study compared with those who underwent surgery alone had a tumor in the resected specimen with a smaller maximum diameter, a greater proportion of $\mathrm{T} 1$ and $\mathrm{T} 2$ tumors, and less advanced nodal disease. These data suggest that regardless of $\mathrm{T}$ or $\mathrm{N}$ stage, all patients derive some benefit from current chemotherapy regimens, in this instance delivered both before and after surgical resection.

Advanced technology staging tools have a central role in the overall assessment of patients with esophageal and gastric cancer. They provide essential information that defines the extent of disease, has the potential to stratify patients for treatment, and most importantly, is used in clinical trials designed to examine novel therapeutic approaches. Unfortunately, because less than $2 \%$ of patients in the United States enter clinical trials, the utility of staging for this most critical task is negated. Furthermore, the overwhelming majority of patients in the United States have advanced disease at the time of presentation, and in this era of effective neoadjuvant therapy, it could be argued that all patients regardless of stage derive some benefit from an aggressive approach to upper gastrointestinal cancer.

Finally, the cost-benefit ratio of preoperative staging for patients with esophageal or gastric cancer is extremely low. In the final analysis, biology always trumps staging, especially for highly lethal cancers for which no methods currently exist to detect malignancies early in their natural history.

\section{The controversy: is MIS an accepted approach for curative treatment of esophageal cancer?}

Pro: Three-field radical open esophagogastrectomy is the treatment of choice for esophageal cancer

\section{Steven De Meester}

Associate Professor in the Department of Cardiothoracic Surgery at the University of Southern California
The first report of an esophageal adenocarcinoma is credited to White in 1898. A review of the literature in 1900 showed only six cases, and at the time, most physicians believed these represented an extension of gastric tumors into the distal esophagus. By the 1950s, scattered reports describing adenocarcinoma developing within a columnar lined esophagus began appearing, and the existence of a primary esophageal adenocarcinoma was established.

Once a rare tumor, adenocarcinoma of the esophagus currently is the cancer with the fastest rising incidence in America. Recent data indicate that since 1975, the rate of increase for adenocarcinoma of the esophagus in the United States has outpaced the next closest cancer, melanoma, nearly threefold [99]. This previously uncommon tumor now ranks within the top 15 cancers among U.S. white males. Similar trends are reported in many European countries, with the highest reported incidence ( 7 per 100,000) in the United Kingdom.

The tremendous increase in the incidence of esophageal adenocarcinoma has led to a complete epidemiologic shift such that in the United States and other industrialized countries, adenocarcinoma has replaced squamous cell carcinoma as the most common esophageal malignancy. This year (2009), the United States will have approximately 13,000 new cases of esophageal adenocarcinoma [100].

To date, no therapy has proved superior to esophagectomy for both the cure and palliation of patients with localized esophageal cancer. The primary goal of surgery is complete (R0) resection of the tumor and surrounding lymph nodes to maximize the opportunity for cure and to minimize the incidence of local recurrence. Findings have confirmed repeatedly that complete surgical resection is the most important prerequisite for the long-term survival of patients with localized esophageal cancer [101]. However, accomplishing this goal is easier for intramucosal tumors than for transmural tumors. Consequently, the surgical approach and the extent of resection should be modified based on the extent of disease present in each patient.

Currently, four main surgical options exist: vagal-sparing esophagectomy without lymphadenectomy, en bloc esophagectomy with thoracic and abdominal lymphadenectomy, transhiatal resection, and a minimally invasive esophagectomy (laparoscopic procedure alone or a combined thoracoscopic and laparoscopic approach). Although few centers offer all four surgical options, each option likely has a place for the appropriate patient, and each offers potential advantages.

\section{Vagal-sparing esophagectomy}

The technique for a vagal-sparing esophagectomy was described in the 1980s by Akiyama et al. [102] from Japan. We have adopted this technique for patients with either 
high-grade dysplasia or intramucosal cancer, and for a subset of these patients, we have confirmed vagal integrity. Vagal preservation has led to a significant reduction in the prevalence of dumping and diarrhea compared with standard esophagectomy with vagotomy [103]. The vagal-sparing procedure is applicable only for patients with intramucosal tumors because no lymphadenectomy is performed. For patients with a visible lesion, it is critical to confirm that the tumor is confined to the mucosa because submucosal invasion imparts a significant risk of lymph node metastases and precludes a vagal-sparing approach. Findings have demonstrated that EUS, even with high-frequency $20-\mathrm{MHz}$ probes, cannot accurately distinguish mucosal from submucosal invasion [86]. Consequently, we currently use endoscopic mucosal resection (EMR) to stage the invasion depth of small tumors $(\leq 1.5 \mathrm{~cm})$ definitively and to determine the appropriateness of a vagal-sparing esophagectomy [104].

\section{En bloc esophagectomy}

To define clearly what can be accomplished with surgery alone for esophageal adenocarcinoma, we evaluated the outcome after 100 consecutive en bloc esophagectomies. The overall survival rate was $52 \%$ at 5 years, and $94 \%, 80 \%$, $77 \%, 24 \%$, and $29 \%$, respectively, for patients with The American Joint Committee on Cancer stages 1, 2a, 2b, 3, and 4 tumor [105]. During a detailed follow-up period (median, 40 months), $69 \%$ of the patients remained free of disease. Systemic disease developed in $31 \%$ of the patients, but local regional recurrence occurred for only one patient $(1 \%)$. Similar excellent local control and survival rates with en bloc resection have been reported by Altorki and Skinner [106].

These data serve to refute the nihilistic attitude that esophageal cancer is systemic and incurable at the time of diagnosis. Moreover, the low incidence of local recurrence after en bloc resection stands in stark contrast to the $20 \%$ to $40 \%$ incidence of local recurrence after transhiatal resection. Because local recurrence after esophagectomy typically results in rapid death from cancer, local control remains a primary goal of therapy for this disease. Currently, en bloc resection is recommended for all patients with limited nodal disease ( $\leq 5$ nodes on EUS) and good cardiopulmonary status without significant medical comorbidities.

\section{Transhiatal versus en bloc resection}

Debate continues with regard to whether the approach and extent of lymphadenectomy alter the survival in cases of surgically treated esophageal adenocarcinoma. Increasingly, evidence exists to show that it does. In a randomized prospective trial, Omloo et al. [107] reported better survival for the group that had en bloc resection than for a transhiatal group. However, the numbers were insufficient to reach statistical significance.

In an analysis of the results for therapy of distal esophageal or gastroesophageal junction (GEJ) adenocarcinoma in a well-defined and stable Finnish population, Sihvo et al. [108] found that patients who underwent en bloc resection with two-field lymphadenectomy had a significantly better survival rate than patients who had a less extensive resection. Interestingly, the 5-year survival rate after en bloc resection was $50 \%$, nearly identical to the 5 -year survival rate reported after en bloc resection in other series. Similarly, the 5-year survival rate of $23 \%$ after non-en bloc resection is similar to that reported in numerous series of transhiatal resections with or without neoadjuvant therapy.

In an effort to compare the outcomes for en bloc and transhiatal resection at our center, we carefully matched patients with tumors of similar stage who underwent one or the other procedure based on the presence or absence of associated medical comorbidities. The study end point was survival at 5 years, and all noncancer deaths were excluded to eliminate concern regarding the different prevalences of medical comorbidities in the groups. All the patients had T3 N1 esophageal adenocarcinoma and a minimum of 20 lymph nodes resected and examined. A significantly better 5-year survival rate was present for those who had en bloc resection than for those who underwent transhiatal resection when more than one to eight nodes were involved. However, with nine or more involved nodes, survival for the two types of resection was similar [109]. This is compelling evidence that the type of resection influences survival for patients with limited regional disease because all patients were followed a minimum of 5 years, and all deaths were due to cancer.

Finally, for a difficult group of patients (those with residual disease after neoadjuvant chemoradiotherapy for esophageal adenocarcinoma), we recently demonstrated that survival after en bloc resection is significantly improved compared with transhiatal resection. The survival rate was $29 \%$ at 3 years and $10 \%$ at 5 years after en bloc resection compared, respectively, with $9 \%$ and $0 \%$ after transhiatal resection [110]. Similar poor results with transhiatal resection are reported by others. This has led to the recommendation that surgery not be offered to patients with residual disease after neoadjuvant chemoradiotherapy. However, long-term cure occurred for some patients after en bloc resection, supporting the importance of local control with this disease.

\section{Minimally invasive esophagectomy}

In the late 1990s, several centers began exploring the potential for a minimally invasive esophagectomy (MIE). Techniques have now been developed for both a 
laparoscopic and a combined thoracoscopic/laparoscopic esophagectomy. The disadvantages of a completely laparoscopic approach include the inherent dangers of dissection near the pulmonary vessels high in the mediastinum and the inability to accomplish a systematic thoracic lymphadenectomy with this approach. However, the vagalsparing procedure is ideally suited to a laparoscopic approach because the esophagus is stripped out of the mediastinum without any dissection, and no lymphadenectomy is necessary for these patients with only highgrade dysplasia or intramucosal cancer. For patients with more advanced cancer, the combined thoracoscopic/ laparoscopic approach offers the advantage of a thoracic lymphadenectomy and has been proved safe and effective in a large series of patients.

Whether an MIE will offer such clear advantages in hospital stay and recovery, with an outcome similar to that for an open procedure, establishing it eventually as the standard approach, similar to what happened with laparoscopic cholecystectomy and antireflux surgery, remains to be determined. In particular, local recurrence rates after a thoracoscopic/laparoscopic esophagectomy need to be determined for an assessment of whether it provides the advantages of complete resection together with the reduced physiologic impact of a minimally invasive approach.

\section{Postesophagectomy morbidity and quality of life}

Esophagectomy with reconstruction is an enormous procedure associated with significant postoperative morbidity for many patients. Some of the most troubling early symptoms, as reported by a patient who underwent esophagectomy for cancer at the age of 40 years, are nausea and gastric retention, dumping, diarrhea, and dysphagia related to anastomotic stricture. As a consequence of these difficulties, as well as recovery from the discomfort of the operation and the slow process of regaining stamina and energy, quality of life decreases significantly during the first 6 weeks after esophagectomy and requires 6 to 9 months for a return to preoperative values. Findings have shown quality of life to be similar after a transhiatal or transthoracic resection.

Long-term functional outcome after esophagectomy was reported by Headrick et al. [111] at the Mayo Clinic. At a median of 5.3 years postoperatively, 7 (13\%) of 48 patients were entirely asymptomatic, $15 \%$ had dumping, $38 \%$ had some degree of dysphagia, and $68 \%$ had gastroesophageal reflux symptoms. Despite these difficulties, the patients' 36Item Short-Form Health Survey quality-of-life scores were better for the physical and emotional roles than the national norm, although the health perception score was lower. Social function scores improved with increasing time after the operation but were adversely affected by the occurrence of an anastomotic leak. Similar follow-up information, together with data on quality of life after esophagectomy, is becoming increasingly important because Barrett's surveillance programs are leading to the identification of earlier-stage tumors, which often are curable.

Consequently, surgeons need to place a major emphasis on evaluating outcome and be willing to modify their procedures to reduce the long-term morbidity of esophageal resection and reconstruction for patients likely to live for many years postoperatively. Efforts at vagal nerve preservation, MIE, and reduction in incidence of anastomotic stricture and leak all are warranted to reduce morbidity and improve quality of life after esophagectomy.

\section{Route of reconstruction and choice of graft}

In most circumstances, the posterior mediastinal route is chosen for reconstruction. The posterior mediastinum, typically a more direct and thus a shorter route for reconstruction, has been shown to have a lower perioperative morbidity rate, leading to better graft emptying than the substernal route. If a substernal route is used, it is important to recognize that the thoracic inlet can impair bolus passage into the graft. At our center, we routinely excise the medial portions of the left clavicle and first rib as well as the left half of the manubrium to prevent this problem.

The most widely used esophageal replacement graft is the tubularized stomach, with colon interposition or small intestine grafts used less frequently as alternatives. Each graft has advantages and disadvantages, but the familiarity, reliable vascular supply, and single anastomosis required with a gastric pull-up make it the first choice for most esophageal surgeons.

When the stomach is not available or for oncologic reasons is unsuitable, a colon interposition based on the ascending branch of the left colic artery is an excellent option for reliable reconstruction. The requirement for three anastomoses, the added time for mobilization, and the potential for redundancy are clear disadvantages with colon interposition, but it also has advantages including a reduced incidence of anastomotic leak and stricture compared with gastric pull-up.

Most esophagectomies involve division of the vagus nerves, and thus a pyloroplasty typically is included with the procedure. Although narrow gastric tubes can empty satisfactorily without a pyloroplasty, some researchers have found that the ischemia and anastomotic leak rates are unacceptably high with narrow gastric tubes. Some centers, particularly in Europe, omit a pyloroplasty and report no significant problems with delayed graft emptying or regurgitation and aspiration events. However, a metaanalysis concluded that pyloric drainage procedures reduce the occurrence of early postoperative gastric outlet obstruction 
after esophagectomy, and in our experience, a pyloroplasty is beneficial [112].

Currently, we use a simple and quick technique that eliminates the risk of leakage. Through a gastrotomy along the lesser curve in an area that will be excised with tubularization of the stomach, we pass a $21-\mathrm{mm}$ circular stapler and excise a portion of the anterior pyloric channel. We have used this technique for more than 2 years at our institution, and it has been very effective.

Most esophageal surgeons anastomose the graft to the cervical esophagus, and although the anastomotic leak rate is higher with this technique, the consequences of a leak are less significant than a leak from an intrathoracic anastomosis. The functional outcomes for high intrathoracic and cervical anastomoses are similar, but the lower the anastomosis, the greater the risk for significant reflux, particularly if it is placed below the level of the azygos vein.

Reflux of gastric juice occurs commonly after esophagectomy and gastric pull-up because the lower esophageal sphincter has been excised, and patients should be advised to eat several hours before lying down at night and to sleep with the head of the bed elevated. Despite these precautions, it has been demonstrated that reflux-induced injury to the esophageal squamous mucosa occurs proximal to the anastomosis, and $50 \%$ of patients have been found to have cardiac columnar metaplasia proximal to the anastomosis, as shown by postoperative endoscopy [113, 114]. Of concern, goblet cells indicative of recurrent Barrett's esophagus can be found in as many as one-half of these patients.

\section{Neoadjuvant chemoradiotherapy}

Three of the drugs most commonly used to treat esophageal cancer (cisplatin, 5- fluorouracil [5-FU], and mitomycin) also enhance radiation effects. To take advantage of these radiosensitizing benefits, a number of clinical trials have been conducted in which radiation and chemotherapy were given before resection. To date, seven randomized prospective trials have been reported (one only in abstract form), and only the trial by Walsh et al. [115] found a survival benefit with neoadjuvant chemoradiotherapy. The other six trials, including the final analysis of the University of Michigan (Urba) trial, found that neoadjuvant chemoradiotherapy offered no survival benefit over surgery alone [116].

Since publication of the Walsh trial, a number of concerns have been raised that call into question the reliability of the results. Much of the concern has focused on three issues: substandard systemic staging because CT scanning was not routinely used; the large number of withdrawals from the protocol and the rationale for them, particularly in the multimodal group; and the inclusion of patients who underwent substandard surgical resections. However, the greatest concern is that the statistical analysis appears to be flawed.

Careful review of the data in the text of the manuscript and the Kaplan-Meier survival curves demonstrate that the median and the 1-, 2-, and 3-year survival data presented in the paper for the multimodal group do not correspond with the survival curve for this group, whereas the curve for the surgery alone group matches appropriately.

In response to this criticism, an erratum has been published suggesting that the figures were mislabeled. However, even this does not correct the problem, and personal requests to the New England Journal of Medicine for independent statistical review of all the data have been denied. All in all, the trial falls short of providing conclusive evidence for the superiority of neoadjuvant chemoradiotherapy before surgery in the treatment of esophageal cancer.

In an attempt to clarify the role of neoadjuvant therapy for esophageal cancer, Fiorica et al. [117] performed a metaanalysis of the published randomized trials. These authors concluded that the pooled estimate of the treatment effect was statistically significant in favor of neoadjuvant chemoradiotherapy followed by surgery for overall survival. However, these authors conceded that exclusion of the Walsh trial led to a loss of statistical significance between groups. Given the problems with the Walsh trial, as outlined earlier, it must be concluded that the metaanalysis does not demonstrate better survival with neoadjuvant therapy than with surgery alone for esophageal cancer.

\section{Neoadjuvant chemoradiotherapy followed by surgery: critical appraisal}

A review of the trials allows several comparisons to be made and a few conclusions to be reached. At the outset, is important to recognize that all the trials suffer from a relatively low power to detect small differences between groups given the small sample size in each trial. Furthermore, variations in the chemotherapy and radiation protocols also confound attempts at a metaanalysis. Despite these issues, it is interesting to note that the 3-year survival rate in the multimodal groups was similar to those in the Walsh (32\%) and Urba (30\%) trials. However, there was a substantial difference in 3-year survival for the surgery alone groups (6\% vs. $16 \%$, respectively). Consequently, the different outcomes in the Walsh and Urba trials were largely a consequence of the difference in survival in the surgery alone groups.

The 3-year survival rate of $6 \%$ in the Walsh trial is less than half the average survival rate for surgery alone in the other five randomized studies $(17 \%)$. Indeed, it is one of the worst surgical survivals ever reported for this disease. 
This certainly gives credence to concerns about the lack of adequate systemic staging and the substandard surgical resections in that trial.

A second conclusion is that neoadjuvant chemoradiotherapy did not reduce the incidence of systemic recurrence. This is consistent with reports that neoadjuvant chemoradiotherapy does not reduce the prevalence of bone marrow micrometastases.

Instead, the major impact of neoadjuvant chemoradiotherapy appears to be better locoregional disease control, in effect compensating for inadequate surgical resections. These trials demonstrate two clear messages: To have an impact on survival for patients with locally advanced esophageal cancer, surgeons need to minimize the incidence of local recurrence by performing an adequate resection, and oncologists need to reduce the incidence of systemic failure with more efficacious chemotherapy.

It is proposed that improved local control may be obtained with higher doses of preoperative radiation. However, even the high doses of radiation used for definitive treatment of esophageal cancer do not reliably eliminate local-regional disease. In addition, the rates of infection, anastomotic breakdown, adult respiratory distress syndrome, long-term respirator use, and mortality all are greater for patients receiving neoadjuvant chemoradiotherapy with radiation in large doses $(>45 \mathrm{~Gy})$ or with high fractionation schedules ( $>200$ cGy/day).

A last conclusion from the trials is that if neoadjuvant chemoradiotherapy offers one glimmer of hope, it is that approximately $20 \%$ of patients who had a complete pathologic response demonstrated excellent survival (64\%) compared with those who had residual disease in the resected specimen (19\%) at 3 years in the Urba trial. A note of caution, however, is that only the clinical stage of the disease was known for these patients before therapy.

Wang et al. [118] have demonstrated with minimally invasive pathologic staging that only patients without lymph node metastases were likely to have a significant treatment response. Obviously, patients with limited disease, especially those with N0 tumor, also are those who do well with resection alone. It is the patients with extensive disease and multiple involved lymph nodes who are most in need of an improved survival with neoadjuvant therapy, and unfortunately, it appears that these are the very patients least likely to achieve a complete pathologic response.

Furthermore, there is increasing evidence that patients who fail to achieve a complete pathologic response not only derive no benefit from the neoadjuvant therapy, but in fact may have a worse survival rate than those who undergo resection alone. This concern was confirmed in a recent publication from the Cleveland Clinic emphasizing the better survival for patients who had T2N0 tumors treated with primary surgical resection than for patients who underwent neoadjuvant therapy [119]. Therefore, in my opinion, until complete pathologic response rates improve or we are able to identify accurately those patients most likely to achieve a complete response, a generic recommendation of neoadjuvant chemoradiotherapy for patients with esophageal adenocarcinoma is unwarranted.

\section{Palliation for esophageal carcinoma}

Surgical resection with esophageal replacement using the stomach or colon remains the standard for both curative treatment and palliation of patients with esophageal cancer. However, for patients with systemic metastases or unresectable local disease, esophageal bypass procedures are associated with high mortality and short postoperative survival rates, and with rare exceptions, are no longer performed. Instead, palliation for these patients is best obtained with the use of coated, self-expanding metal stents. Advancements in technology have revolutionized both the ease of placement and the safety of esophageal stents. As a consequence, few indications remain for the use of photodynamic therapy (PDT) or laser with these patients [120].

\section{New horizons in the treatment of esophageal cancer}

Significant strides continue to be made in the treatment of patients with cancer. One area certain to play an increasingly important role is chemosensitivity testing. A better understanding concerning the molecular impact of chemotherapeutic agents and new methods for rapid, reliable, and less labor-intensive analysis of the genes involved have opened the door for testing responsiveness to a steadily expanding list of chemotherapy agents. Other treatment strategies that may play a role include the use of angiogenesis inhibitors and the use of immunotherapy. However, early detection while the tumor still is intramucosal offers the surest way to cure esophageal cancer. Thus, surveillance endoscopy for patients with Barrett's esophagus and perhaps endoscopic screening of high-risk patients with longstanding reflux may be the most helpful strategy currently.

Con: Total MIS esophagectomy is the treatment of choice for esophageal cancer

James D. Luketich

Chief of the Heart, Lung and Esophageal Surgery Institute at the University of Pittsburgh Medical Center

Arjun Pennathur

Since the initial description of laparoscopic fundoplication in 1991 [121], esophageal surgeons have increasingly incorporated the techniques of MIS into their practice. This is supported by several surgical series that have documented the benefits of MIS for the treatment of 
gastroesophageal reflux disease [122-124] and achalasia [125-127]. A consistent finding of these reports is the equivalent efficacy and decreased recovery times of laparoscopic surgery compared with traditional open surgery. These reports have led to increasing surgical referrals for the management of these diseases, although alternative medical therapies are available [128].

Minimally invasive surgery offers several potential benefits for patients with esophageal cancer. Esophagectomy is associated with significant morbidity and mortality rates $[129,130]$. The risks associated with open esophagectomy have led to increasing interest among oncologists for treating patients with definitive chemoradiation alone [131, 132]. Unfortunately, some of these data have been extrapolated to healthy patients with high-grade dysplasia or early-stage esophageal cancer in whom very high 5-year survival rates can be anticipated after esophagectomy. It is critical for surgeons to refine the esophagectomy technique and to reduce the risks associated with it.

In an effort to reduce the risks of esophagectomy, we have adopted a minimally invasive approach to the procedure [133]. Currently, MIE is being adopted in many centers. This approach has several potential benefits.

In this report, we summarize the technique and results of MIE and the studies that have compared a minimally invasive approach to an open approach for esophagectomy.

\section{MIE technique}

The technique for MIE has evolved as our experience with other minimally invasive foregut procedures, such as laparoscopic Heller myotomy, repair of giant paraesophageal hernias, and staging for esophageal cancer, has grown. To date, we have performed more than 500 MIEs at the University of Pittsburgh Medical Center.

Initial attempts at MIE were hybrid operations combining traditional open surgery with minimally invasive techniques. The first such report by Collard et al. [134] in 1993 included 12 patients who underwent thoracoscopic mobilization of the esophagus followed by laparotomy and preparation of the gastric conduit. In that series, two patients required conversion to thoracotomy because of bleeding. Several subsequent reports have demonstrated the feasibility of this approach. However, no definitive benefit has been shown compared with open esophagectomy [135, 136].

A completely laparoscopic transhiatal esophagectomy also has been described. The largest series, published by DePaula et al. [137] in 1995, described 48 patients who required esophagectomy predominantly for end-stage achalasia secondary to Chagas' disease. Only two patients required conversion to laparotomy.

The first experience with MIE in the United States was not reported until 1997, when Swanstrom and Hansen [138] described a carefully selected group of nine patients with small tumors, benign strictures, and Barrett's disease. Eight of these patients underwent a totally laparoscopic transhiatal esophagectomy. The remaining patient required the addition of a right video-assisted thoracic surgery (VATS) procedure.

\section{MIE at the University of Pittsburgh}

Similar to these early reports, our initial efforts at MIE were through the transhiatal approach. However, although this simplifies patient positioning and does not require single-lung ventilation, we found that the disadvantages were significant. The small working space through the hiatus allowed limited access to the middle and upper third of the esophagus and made any thoracic lymph node dissection extremely difficult. Because of this, our current approach includes a right VATS to mobilize the thoracic esophagus followed by laparoscopy to prepare the gastric tube. Patients found to have bulky nodal metastases by CT scan or staging laparoscopy are not thought to be candidates for MIE, and consideration is given to either an open operation or definitive chemoradiation.

We have described our technique in detail and published our results for 222 consecutive patients who have undergone MIE at the University of Pittsburgh [92]. Esophagectomy was performed with thoracoscopy, laparoscopy, and cervical anastomosis. Although early in the series we selectively performed MIE for patients with smaller tumors and no previous therapy, $35 \%$ of the patients in this series had been treated with chemotherapy and $16 \%$ with radiation. In addition, $25 \%$ of the patients had undergone prior open abdominal surgery. For 206 of the patients (93\%), MIE could be completed as planned. No emergent conversions to an open procedure were necessary for bleeding. The operative mortality rate was $1.4 \%$. This very low mortality rate compares favorably with that for the largest series of open esophagectomy (Table 1). The rate of anastomotic leak in this series was $11.7 \%$. The median intensive care unit (ICU) stay was 1 day, and the hospital stay was 7 days. The survival rate was comparable with that in open series. In addition, the quality of life was well preserved.

We also have reported our results after minimally invasive Ivor Lewis esophagectomy for 50 patients at the University of Pittsburgh [139]. This is a good option, especially for patients with extensive involvement of the cardia in whom the conduit may not reach to the neck.

\section{Prone positioning}

Another modification of the thoracoscopic approach is positioning of the patient in a prone position [140]. The potential advantage of this technique is that the lung and blood do not obscure the view of the esophagus. In fact, 
Table 1 Comparison of minimally invasive and open esophagectomy series

\begin{tabular}{|c|c|c|c|c|c|c|}
\hline & Year & $n$ & Approach & OR (AQ39) & LOS (days) & Mortality (\%) \\
\hline \multicolumn{7}{|l|}{ Total MIE } \\
\hline DePaula [137] & 1995 & 12 & Lap THE & 4.3 & 7.6 & 0 \\
\hline Swanstrom and Hansen [138] & 1997 & 9 & Lap THE & 6.5 & 6.4 & 0 \\
\hline Watson et al. $[44,154]$ & 2000 & 7 & MIE & 4.4 & 12 & 0 \\
\hline Luketich $[82,125,133]$ & 2003 & 22 & MIE & NR & 7 & 1.4 \\
\hline Nguyen $[61,142,143]$ & 2003 & 46 & MIE & 5.8 & 8 & 4.3 \\
\hline \multicolumn{7}{|l|}{ Hybrid } \\
\hline Gossot [155] & 1995 & 29 & VATS/laparotomy & $2.3^{\mathrm{a}}$ & NR & 3.8 \\
\hline Jagot $[156]$ & 1995 & 9 & Lap-assisted & 8.5 & 10.3 & 0 \\
\hline Liu [157] & 1995 & 20 & VATS/laparotomy & $4.6^{\mathrm{a}}$ & 19 & 0 \\
\hline Peracchia $[158]$ & 1997 & 18 & VATS/laparotomy & 5.6 & NR & 5.5 \\
\hline Law [159] & 1997 & 18 & VATS/laparotomy & 4 & NR & 0 \\
\hline Kawahara [160] & 1999 & 23 & VATS/laparotomy & $1.8^{\mathrm{a}}$ & 26 & 0 \\
\hline Smithers $[144,161]$ & 2001 & 15 & VATS/laparotomy & 5.0 & 12 & 3.3 \\
\hline Osugi [147] & 2003 & 80 & VATS/laparotomy & 3.7 & NR & 0 \\
\hline \multicolumn{7}{|l|}{ Open } \\
\hline Mathisen [162] & 1988 & 10 & TS (64)/IL (40) & NR & NR & 2.9 \\
\hline Lerut [163] & 1992 & 19 & Open (varied) & NR & 18 & 9.6 \\
\hline Orringer [164] & 1999 & 10 & THE & NR & $7^{\mathrm{b}}$ & 4 \\
\hline Swanson [165] & 2001 & 25 & Three-hole & NR & 13 & 3.6 \\
\hline Bailey [166] & 2003 & 17 & Open (varied) & NR & NR & 9.8 \\
\hline Rizk [167] & 2004 & 51 & Open (varied) & NR & $23^{\mathrm{c}}$ & 6.1 \\
\hline
\end{tabular}

OR operating room; LOS length of hospital stay; Lap laparoscopic; THE transhiatal esophagectomy; MIE minimally invasive esophagectomy; VATS video-assisted thoracic surgery; NR non-reportable; TS thoracoabdominal; IL Ivor-Lewis

${ }^{a}$ VATS portion only

${ }^{b}$ In last two years of series

${ }^{c}$ Pts. with complications

Reprinted from Kent et al. [191]

single-lung ventilation may be used with $\mathrm{CO}_{2}$ insufflation because the ipsilateral lung will fall away from the field due to gravity.

The largest reported experience with prone positioning is described by Palanivelu et al. [141] from India. All 130 patients in this series had squamous cell cancer of the midthoracic esophagus, and only one patient received neoadjuvant therapy.

With prone positioning, the esophagus is first mobilized thoracoscopically using three ports with the patient in the prone position. The patient then is turned to the lithotomy position, and mobilization of the esophageal hiatus and stomach is performed laparoscopically. A minilaparotomy then is performed for tumor extraction, creation of the gastric tube, and pyloroplasty. The procedure is concluded with a cervical anastomosis.

Early results after this procedure are encouraging. The median ICU stay was 1 day, and the overall mortality rate was $1.5 \%$. The major morbidity rate was $11 \%$, and the anastomotic leak rate was only $3 \%$. Stage-specific survival after this procedure was equivalent to that of open series. These results of low morbidity and mortality rates favor a minimally invasive approach.

\section{Comparison of MIE with open esophagectomy}

For optimal outcomes, MIE techniques require advanced laparoscopic and thoracoscopic skills. For this reason and due to the inherent constraints of visualization and instrumentation, the operative times for MIE are longer and encompass a wide range (3.7-7.5 h) (Table 1). Most open esophagectomies can be performed within 3 to $6 \mathrm{~h}$. Although the time required for MIE is longer, we believe that the minimally invasive approach translates into a lower incidence of postoperative pain, fewer pulmonary complications, and a shorter hospital stay. However, to date, no randomized studies have compared outcomes between open esophagectomy and MIE. Nevertheless, a few published single-institution series have compared a minimally invasive approach with historical controls. 
In an early study comparing minimally invasive $(n=18)$ and open $(n=16)$ esophagectomy, Nguyen et al. [142, 143] found that the mean operative time $(364 \mathrm{~min})$, blood loss (297 ml), and length of ICU stay (6.1 days) were less than with open transthoracic esophagectomy (437 min, $1046 \mathrm{ml}$, and 9.9 days, respectively) or blunt transhiatal esophagectomy (391 min, $1142 \mathrm{ml}$, and 11.1 days, respectively). The incidence of respiratory complications (pneumonia, pulmonary embolism, respiratory failure) was similar between the groups.

It should be emphasized that the groups in this retrospective comparison had significant differences. The open patients had more advanced cancers and were treated by a group of four surgeons with variable experience, whereas the MIE procedures were performed by a single surgeon with expertise in minimally invasive esophageal surgery. The open operations were performed several years before the MIE procedures, so differences in practice may account for the longer hospital stays.

Another study that evaluated the benefits of MIE was reported by Narumiya et al. [144]. In this study, 40 patients who underwent esophagectomy were prospectively randomized to either a conventional open approach or a "mini" thoracotomy and "mini" laparotomy. The patients who had the more limited incisions were noted to have significantly fewer narcotic requirements and a shorter hospital stay. It is reasonable to assume that the benefits would be even more significant had the patients undergone a true MIE rather than a less extended open operation.

In a more recent study, Smithers et al. [145] reported the outcomes for a total of 446 patients who underwent esophagectomy. The approaches used for these patients were open (thoracotomy and laparotomy for 114 patients), thoracoscopically assisted (thoracoscopy and laparotomy for 309 patients), and total MIE (thoracoscopic and laparoscopic procedure for 23 patients). The minimally invasive group experienced less blood loss and a shorter hospital stay. They also had higher stricture rates. No significant differences in the lymph node retrieval or survival were noted when the groups were compared stage for stage.

In another study, Braghetto et al. [146] reported the results for a total of 166 patients, of whom 60 underwent transthoracic esophagectomy, 59 underwent transhiatal esophagectomy, and 47 underwent MIE. The early and late complication rates were significantly decreased in the MIE group.

Osugi et al. [147] compared 72 patients who underwent esophagectomy using three-field lymphadenectomy and the standard posterolateral thoracotomy with 77 patients who underwent the procedure using a thoracoscopic (VATS) assisted approach with a minithoracotomy. The mean number of lymph nodes removed, the blood losses, and the morbidity rates were similar. The decrease in vital capacity was less in the VATS group. The survival rates were similar.

In summary, a review of these studies comparing a minimally invasive approach to an open approach shows favorable results with regard to a minimally invasive approach.

\section{Survival and quality of life after MIE}

The other issue in assessing the benefits of MIE is the quality of life after surgery. There are limited data on quality of life after esophagectomy. In an interesting study, Taguchi et al. [148] evaluated the impact of the approach to esophagectomy on pulmonary function tests, exercise tolerance, and quality of life for 51 patients. These authors compared the outcomes of patients who underwent a standard posterolateral thoracotomy versus thoracoscopic approach. All the patients had a laparotomy and a cervical anastomosis. The thoracotomy group had less decline in vital capacity, and dyspnea-limiting exercise tolerance was more common. The maximum oxygen uptake was similar in the two groups. No differences in survival were noted between the groups.

In our series, the quality of life was evaluated by administering validated quality-of-life and disease-specific questionnaires to patients who had undergone MIE. Overall, both the postoperative dysphagia and heartburn scores were excellent, and only $4 \%$ of the patients questioned had significant reflux. Also, the overall quality of life as measured by the Short-Form 36 was no different from that of age-matched control subjects. In summary, the quality of life appears to be well preserved after MIE.

\section{New developments in MIE}

Robotic MIE Another modification to MIE is the use of robotic assistance. Early attempts restricted the use of the robot to the thoracic mobilization. Although the operative time was lengthy, the robot was thought to eliminate some of the ergonomic difficulties with standard thoracoscopy, and in addition could provide the surgeon with a true threedimensional field of view [149, 150]. Subsequently, entirely robotic esophagectomies have been performed, using both Ivor Lewis [151] and transhiatal approaches [152].

The advantages of the robot are likely to be most significant with the transhiatal approach. The working space through the hiatus is quite small, and dissection becomes increasingly difficult as it is carried toward the carina. This difficulty led us to abandon, in part, the laparoscopic transhiatal esophagectomy in favor of a three-hole technique. These difficulties are decreased with the graded motion and several degrees of rotational freedom used in the robotic system. 
All the publications on robotic esophagectomy are case reports or small series. The largest series, published only as an abstract, reported on nine patients who underwent a totally robotic transhiatal esophagectomy [153]. In that report, the mean operative time was $5 \mathrm{~h}$, and the average length of hospital stay was 8 days. This study and others demonstrate the technical feasibility of robotically assisted esophagectomy. An appreciation for the benefits of the robot, if any, will not be possible until experience with the technique increases significantly.

\section{Conclusions}

Minimally invasive esophagectomy can be performed with acceptable morbidity, low mortality, and oncologic results potentially equivalent to those for the open approach. A multi-institution trial is underway to document the potential advantages of MIE. This trial is sponsored by the Eastern Cooperative Oncology Group (ECOG 2202), with the participation of multiple centers across the United States and with the University of Pittsburgh serving as the coordinating center. The completion of this study hopefully will demonstrate the benefits of the procedure and document that its advantages can be realized at other centers (Table 1 [133, 137, 138, 142, 147, 153-167]).

\section{The controversy: do all patients with curable gastric cancer require radical open resection?}

Pro: Open regional D2 lymphadenectomy is the standard of care for all patients with curable gastric carcinoma

\section{Martin Karpeh}

Chief of Surgical Oncology at the State University of New York-Stony Brook

In the West, the incidence of adenocarcinoma involving the stomach has diminished significantly over the past century. In the United States, gastric cancer dropped from being the most common cause of cancer death in the 1940s to the current rank of 14th. In 2007, the American cancer society data reported 21,260 new cases of stomach cancer and 11,210 deaths, compared with 112,340 cases of colon cancer. The change in cancer incidence, coupled with the precipitous drop in the number of operations for benign ulcers, has had a major impact on the number of stomach operations performed by most surgical residents.

Obtaining a complete surgical resection is an essential component in the curative treatment of this disease. Moreover, understanding the natural history of gastric cancer and its patterns of progression is critical to achieving an R0 resection [168]. This understanding has evolved considerably in the past decade [169]. The concept that all gastric cancers require a radical en bloc total gastrectomy has been modified to reflect both tumor and patient characteristics. Tumor size, depth of invasion, and extent of lymph node involvement now clearly determine the extent of surgery needed to achieve an R0 resection.

The extent of lymph node dissection needed for cure has been a point of controversy in gastric cancer surgery for decades. The rationale for performing a D2 lymphadenectomy is to increase the probability of clearing local regional lymph nodes at risk for clinical and occult metastases. In an analysis of 100 consecutive T1-3 N0 and T1-3 N1 gastric cancers, Siewert et al. [170] demonstrated a high frequency of micrometastases in clinically negative nodes. In this multivariate analysis, the presence of micrometastases was independently associated with a worse prognosis. Their results suggest that the D2 lymphadenectomy was advantageous for patients with either lymph node metastases to perigastic level 1 nodes or node-negative trans-serosal tumors (pT3), for whom the risk of missing micrometastases would be greatest.

According to the guidelines of the Japanese Research Society for Gastric Cancer, the D1 dissection (formerly R1) involves the removal of perigastric (level 1) nodes located directly along the lesser and greater curvatures of the stomach (stations 1-6). An incomplete level 1 dissection is labeled a D0 lymphadenectomy. The D2 lymphadenectomy removes the aforementioned perigastic nodes (stations 16), the nodes along the left gastric artery (station 7), the common hepatic artery (station 8 ), the celiac trunk (station 9), the splenic hilum and the splenic artery (stations 10 and 11). The "classic" D2 lymphadenectomy included a distal pancreatectomy and splenectomy to resect stations 10 and 11. Currently, the pancreas and spleen are rarely resected when a D2 lymphadenectomy is performed in the absence of direct tumor invasion [171, 172].

With the aforementioned background, a number of prospective randomized trials have attempted to evaluate the effect of performing the larger D2 lymphadenectomy compared with a standard D1 (Table 1). To date, no survival advantage has been demonstrated for the $\mathrm{D} 2$ procedure, but increased morbidity and mortality have been attributed to the larger lymphadenectomy. Hartgrink et al. [173] evaluated the 11-year follow-up study of the patient entered into the largest lymphadenectomy trial published to date. In a subset analysis by $\mathrm{N}$ stage, the authors found no benefit of the D2 lymphadenectomy for N0 or N1 patients ( 1 to 6 positive nodes). Patients with 7 to 15 positive nodes had a better survival after the D2 node dissection than after the standard D1. These authors concluded that an extended lymph node dissection may offer a cure for patients with N2 disease, but cautioned that extended lymph node 
dissections may not be of benefit if morbidity and mortality can be avoided.

We have the ability to identify which gastric cancer patients are likely to benefit from the more extended D2 lymphadenectomy based on their T-stage and to a lesser extent on tumor size. In evaluating the $\mathrm{T}$ - and N-stage of the 711 patients entered into the Dutch trial, it is not surprising that the trial was negative with regard to survival. In this trial, $75 \%$ of the patients had either a $\mathrm{T} 1$ or $\mathrm{T} 2$ tumor, and nearly 50\% were node negative [173, 174]. Such a patient population is not likely to have a high metastatic lymph node burden.

We know that properly staged node-negative T2a and T2b tumors do very well after resection [175], making it even more difficult to show a survival difference. In contrast, nearly $80 \%$ of patients with T3 tumors will be node positive, and $40 \%$ will have seven or more positive nodes (N2 disease), as shown by routine hematoxylin and eosin staining. These patients do very poorly and were underrepresented in the Dutch trial. For studying the impact of an extended lymphadenectomy, T3 patients would have been the appropriate population. With these data in mind, the subset analysis becomes even more relevant.

The opposite situation was observed in the U.S. trial of postoperative chemoradiation for gastric cancer, which randomized patients to observation or postoperative chemoradiation after a curative gastrectomy for gastric cancer [176]. An analysis of the tumor characteristics of the patients treated in that trial showed that $85 \%$ had $\mathrm{T} 3$ and node-positive tumors, yet the extent of lymphadenectomy was D2 for only $10 \%$ and D1 for $36 \%$, with $54 \%$ having what was described as a D0 resection. Hundahl et al. [177] further analyzed these data and found that undertreatment, as defined by a high Maruyama index, was associated with the D1 and D0 lymphadenectomy as well as poor survival independent of the adjuvant treatment received.

The lesson learned from these to trials is that the treatment should match the disease such that patients with advanced T3 tumors, who are at risk of having extensive nodal disease, may benefit from a more extensive node dissection provided it is performed safely. On the contrary, more early-stage disease (T1 or T2a) can be treated with a standard D1 node dissection or less depending on the characteristics of the tumor [178].

Higher morbidity and mortality rates have been associated with the D2 lymphadenectomy than with the standard D1 [119, 179-181]. Both the British and Dutch trials found that the practice of routine distal pancreatectomy and splenectomy significantly increased postoperative morbidity and mortality [119, 127]. A proper D2 can be performed without the need for distal pancreatectomy or splenectomy.

A recent prospective randomized trail of D1 versus D2 lymphadenectomy avoiding pancreaticosplenectomy demonstrated no increase in morbidity or mortality in a multicenter series of well-trained Italian surgeons [182]. Another randomized trial of D2 versus D2 plus paraaortic nodal dissection also showed a very low morbidity and mortality rate [183]. Both trials involved specialty centers and surgeons quite familiar with performing D2 lymphadenectomy, suggesting that experience matters.

Applying laparoscopic techniques to perform a D2 lymphadenectomy introduces another layer of complexity that will require study for an understanding of what, if any, benefit it confers. Preliminary data suggest that a laparoscopic distal gastrectomy can be performed safely, but the numbers are too small to provide meaningful data [184]. Additional benefits of laparoscopic gastrectomy were reduced blood loss, shorter time until resumption of eating, and shortened hospital stay. However, only 20 open and 21 laparoscopic lymphadenectomy procedures were performed in the study.

The incidence of gastric cancer continues to decrease in the United States and the Western world, suggesting that the disease is being diagnosed at an earlier stage. The opportunities to gain sufficient experience performing a safe open D2 lymphadenectomy are becoming less frequent. This issue is even greater when it comes to learning how to do the operation laparoscopically. The results of adjuvant treatment for gastric cancer suggest that surgery still is the essential component if cure is to be achieved. Without a sufficient volume of cases, my concern is that laparoscopy will not be put to the proper tests for the answers we need before we introduce it into standard practice.

Con: MIS approaches (endomucosal resection, laparoscopic gastrectomy, and sentinel node) are appropriate for selected patients with curable gastric cancer

\section{Ichiro Uyama}

Department of Surgery at the Fujita Health University School of Medicine

Endoscopic mucosal resection has been established as an advanced first-choice treatment for early gastric cancer without lymph node metastasis. When lymph node metastases are present, it is controversial whether laparoscopic surgery should be performed as treatment. Although the extent of lymphadenectomy is being debated in other parts of the world, Japan has suggested D2 lymph node dissection as the standard of care for carcinomas with lymph node metastasis since the 13th edition of the Japanese Classification of Gastric Carcinoma (JCGC) was published in June 1999 [185]. According to the latest edition of the JCGC, curable gastric cancers with lymph node metastasis should be treated with laparoscopic D2 dissection. However, some practitioners have yet to acquaint 
themselves with the technical difficulties it poses. This study describes the techniques used and the initial results for laparoscopic D2 dissection (according to the latest edition of the JCGC) used to treat gastric cancer.

\section{Selection of patients}

EMR Endoscopic mucosal resection is indicated for patients with well- or moderately differentiated mucosal cancer, that is, tumors smaller than $2 \mathrm{~cm}$ in diameter with no lymph node metastasis [186].

Laparoscopic gastrectomy with lymph node dissection The indications for laparoscopic surgery to treat gastric cancer in our study included contraindications to EMR, depth of tumor invasion (i.e., tumor confined to the subserosal layer [cT2]), and no evidence of lymph node metastasis or metastasis confined to group 3 nodes (less than cN2). Bulky tumor was a contraindication. Neither tumor location nor histologic type was considered in the selection criteria. Patients with medical conditions that precluded general anesthesia were not enrolled in this study.

\section{Operating room setup}

All procedures were performed with the patients under general anesthesia and in the supine position with their legs apart. A head-up tilt $\left(20^{\circ}\right)$ was used to prevent the transverse colon or small intestine from visually compromising the operative field. The primary surgeon stood to the patient's right, with the first assistant on the patient's left and the camera operator between the legs. A video monitor was placed over the patient's head.

\section{Surgical technique}

A pneumoperitoneum was established using the open technique, and six ports were placed as shown in Fig. 1. The flexible laparoscope (Olympus Corporation, Tokyo, Japan) was introduced through the infraumbilical port.

Distal gastrectomy [187, 188]

Lymph node dissection and gastric resection: The gastrocolic ligament including the lymph node station no. 4sb lymph nodes was divided proximally about $3 \mathrm{~cm}$ from the left epiploic arcade toward the lower pole of the spleen using laparosonic coagulating shears (LCS) or a vesselsealing system (LigaSure). The left gastroepiploic vessels were exposed using the dissector and divided with clips. The lymph node station no. 4sb lymph nodes were divided from the greater curvature using the LCS or LigaSure.

After division of the gastrocolic ligament, including lymph node station no. $4 \mathrm{~d}$, distally toward the pylorus, attention was directed toward the inferior edge of the

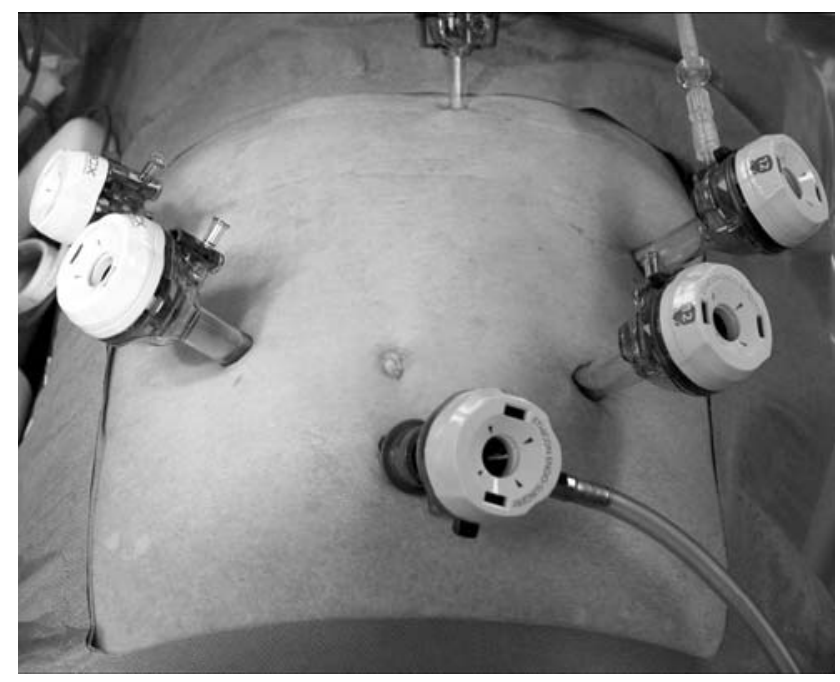

Fig. 1 Placement of ports

pancreas. In focusing on this region, the middle colic vein, superior mesenteric vein, gastrocolic trunk, and right gastroepiploic vein were exposed, and lymph node station no. $14 \mathrm{v}$ was dissected using the LCS. The roots of the right gastroepiploic vessels were divided with clips, and lymph node station no.6 lymph nodes were dissected from the duodenum using the LCS (Fig. 2).

The duodenum was transected $1 \mathrm{~cm}$ distal to the pylorus using an endoscopic stapling device as a prelude to division of the right gastric vessels. Next, the proper hepatic artery was skeletonized using the LCS. This procedure allowed the dissection of lymph node station no.12a and identification of the root of the right gastric artery, which was subsequently divided by clipping.

After the dissection of lymph node station nos.12a and 5 , tape, which encircled the common hepatic artery, was

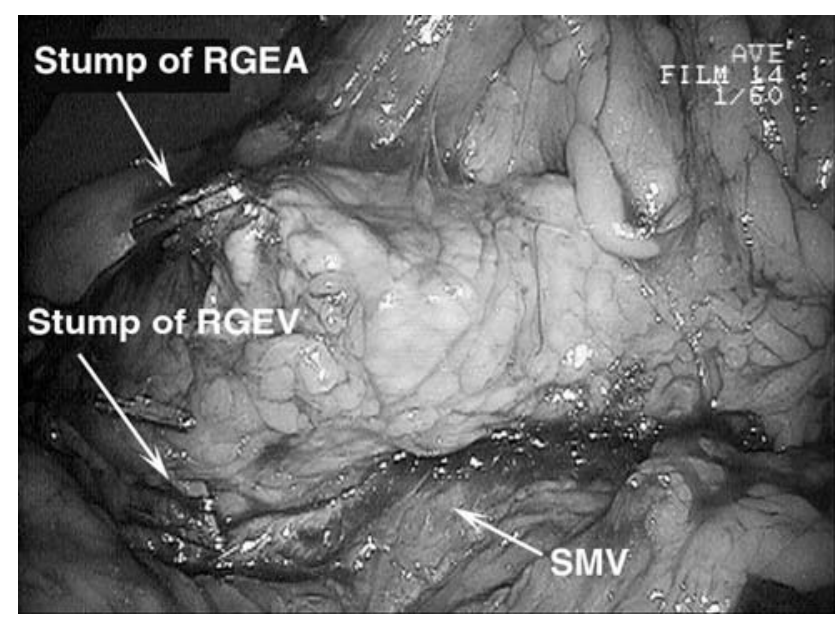

Fig. 2 Complete dissection of \#6 and 14v lymph nodes. RGEA, right gastroepiploic artery; RGEV, right gastroepiploic vein; SMV, superior mesenteric vein 
retracted caudally. After the retraction, the common hepatic artery was skeletonized, and lymph node station no. 8a was dissected using the LCS. Next, the root of the splenic artery was isolated and taped with the vessel tape.

The proximal splenic artery was skeletonized along the upper border of the pancreas, and lymph node station no. $11 \mathrm{p}$ was dissected using the LCS. The left gastric vein was divided, and the root of the left gastric artery was exposed and divided with double clips, allowing dissection of the lymph node station no.7 lymph nodes. Further dissection of the lymph node station no.9 lymph nodes was added proximally. The lymph node station nos. 1 and 3 lymph nodes were dissected together with skeletonization of the upper third of the lesser curvature.

After creation of the minilaparotomy (length, $4-5 \mathrm{~cm}$ ) on the upper abdomen, the stomach was transected via this minilaparotomy extracorporeally, and an en bloc resection of the stomach and D2 lymph nodes was completed. The complete lymph node dissection is shown in Fig. 3.

Reconstruction: In the reconstruction, the intracorporeal anastomosis was performed with a Roux-en-Y gastrojejunostomy using linear staplers.

Total gastrectomy $[189,190]$

Lymph node dissection and gastric resection: Under laparoscopic vision, the body and tail of the pancreas and spleen were mobilized from the retroperitoneal space. After ligation and division of the splenic vein and artery with the vascular stapler, splenectomy was performed to remove the lymph node station no. 10 lymph nodes. Next, the mobilized pancreas was retracted caudally, and the lymph node station no. 11d lymph nodes were dissected (Fig. 4). Finally, the lymph node station nos. 6, 5, 12a, 8a, 9, 7, and $11 \mathrm{p}$ lymph node dissections were performed as described earlier for distal gastrectomy.

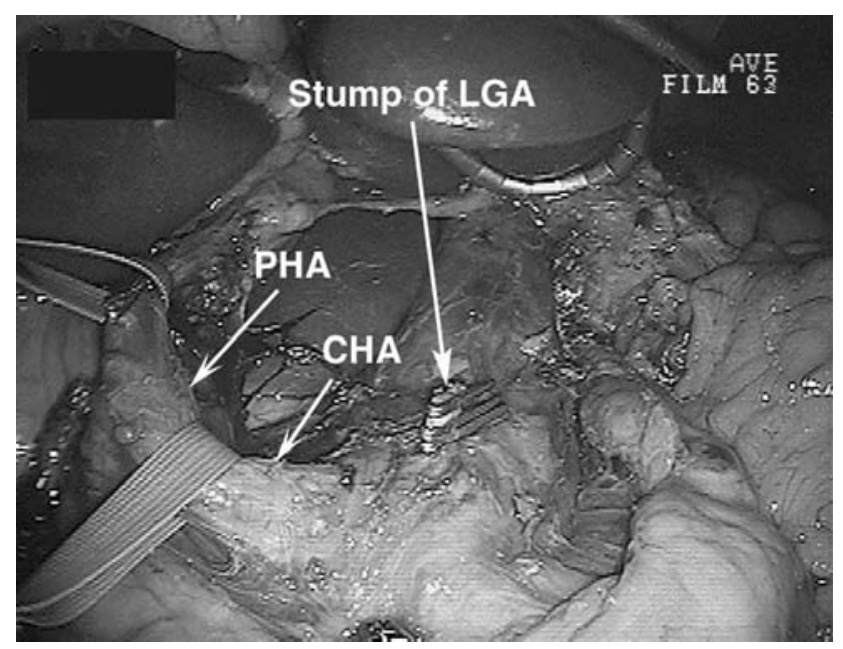

Fig. 3 Completion of radical D2 lymph node dissection. LGA, left gastric artery; PHA, proper hepatic artery; CHA, common hepatic artery

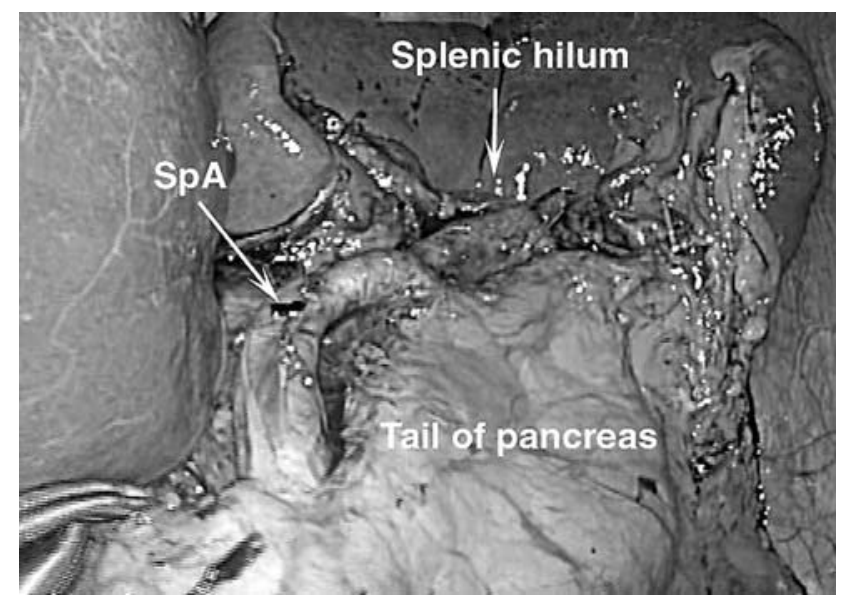

Fig. 4 Complete dissection of \#11d lymph node dissection. SpA, splenic artery

Reconstruction: An intracorporeal esophagojejunostomy was created using the linear stapler, as shown in Fig. 5, and the R-Y limb jejunojejunostomy was made extracorporeally via minilaparotomy.

\section{Results}

From July 1999 to December 2006, we performed laparoscopic gastrectomies with lymph node dissection for 462 patients who had gastric cancer. In this series, 120 cases were managed laparoscopically with standard lymph node dissection (D2), and 330 were managed with limited type dissection. There were no mortalities, and postoperative recovery was uneventful.

The average operative time was $284 \mathrm{~min}$ (range, 212$458 \mathrm{~min}$ ), which was significantly longer than for the corresponding open surgery. The average blood loss was $76 \mathrm{~g}$ (range, 10-386 g), and blood transfusion was not required for all the patients. The average number of lymph nodes harvested per patient using the D2 resection was 58.4 (range, 37-104). As determined by unpaired Student's $t$ test, this number was significantly different from the number of nodes harvested (average, 42.8) in the laparoscopically limited type lymph node dissection $(n=330)$, as we reported previously. Moreover, there was no statistical difference between the laparoscopic and conventional open D2 dissections in terms of the number of nodes harvested (average, 58.4 and 55.2, respectively). To date, there have been nine cases of recurrence in 450 patients treated for gastric cancer $(2 \%)$. In addition, no port-site recurrences have been reported.

\section{Discussion}

Laparoscopic surgery is becoming increasingly popular as a viable option for the management of gastric cancer in the 
Fig. 5 Intracorporeal esophagojejunostomy by linear stapled end-to-side anastomosis

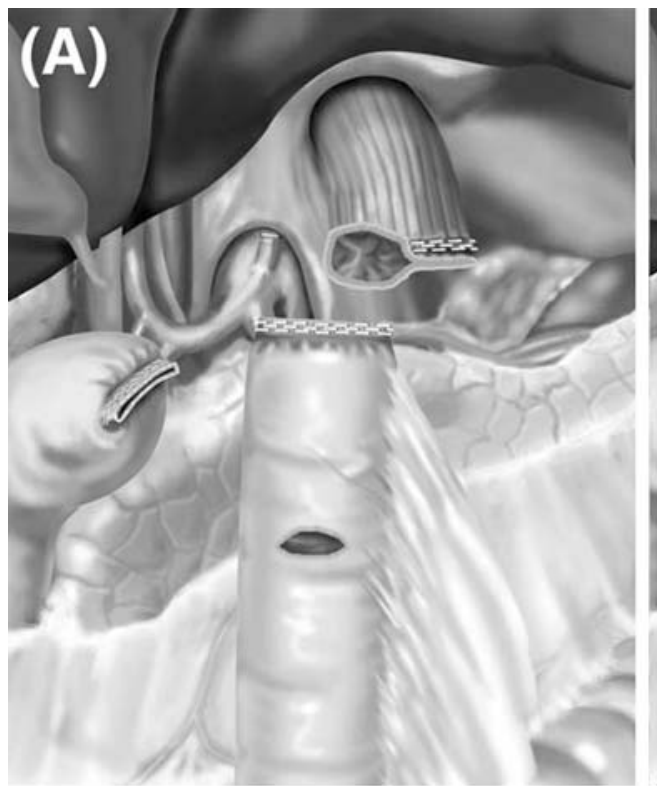

\section{(B)}
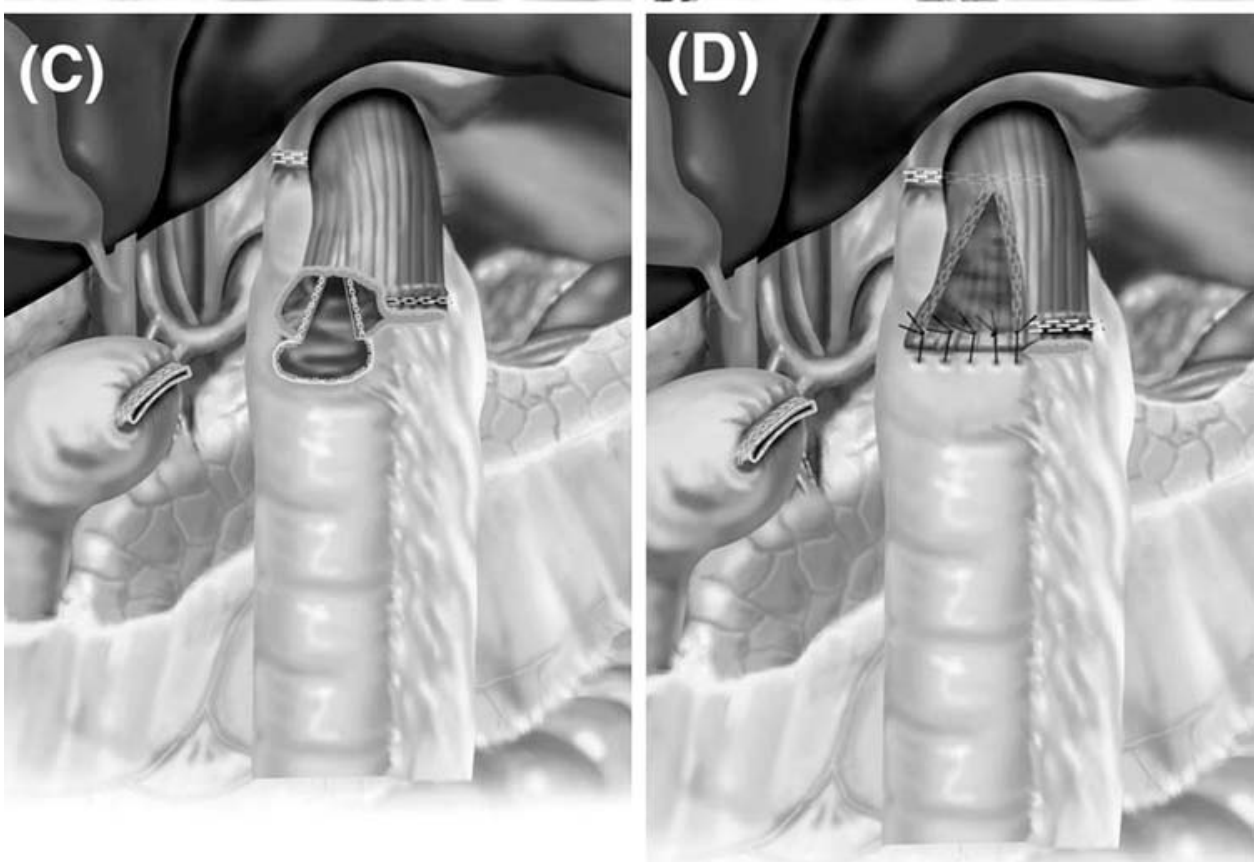

absence of lymph node metastasis. Despite its growing appeal, laparoscopic gastrectomy for curable gastric cancer with lymph node metastasis remains very controversial. Laparoscopic D2 lymph node dissection is technically difficult, and many surgeons have indicated that the procedure at station nos.12a, 14v, 11p, and 11d is difficult and hazardous. However, our experience has been decidedly different. In fact, we found these dissections to be both feasible and technically safe. Although the question arises whether our laparoscopic D2 dissection is really an en bloc dissection or not. Our lymph node dissection is not a "pickup dissection," but rather, a complete lymphatic tissue "en bloc dissection" equivalent to an open surgery.
Laparoscopic surgery for the treatment of advanced gastric cancer also must consider the phenomenon of portsite recurrences as well as the important radical lymph node dissection. Port-site recurrences need further clarification, but investigators have speculated that they probably are caused by some combination of the following factors: tumor manipulation, failure to isolate the tumor, and forceful extraction of the surgical specimen. The literature has yet to report any such recurrences after laparoscopic radical gastrectomies. Moreover, we have not experienced port-site recurrences after laparoscopic gastrectomy for gastric cancer. Therefore, from this experience, our impression is that careful visceral manipulation combined 
with systematic en bloc D2 lymph node dissection laparoscopically is safe and feasible for the treatment of curable advanced gastric cancer. However, the current practice of laparoscopic surgery for curable gastric cancer with lymph node dissection should be confined to experienced surgeons due to insufficient elucidation of port-site recurrence mechanisms. Furthermore, randomized controlled studies are needed in this field.

Although a substantial number of cases and randomized control studies are necessary for an objective evaluation of our procedure's benefit and curability potential, we believe that laparoscopic surgery for curable gastric caner is both technically feasible and safe and has many advantages over conventional surgery. The laparoscopic approach is associated with minimal postoperative pain, quick mobilization, short hospital stay, and better cosmesis.

Open Access This article is distributed under the terms of the Creative Commons Attribution Noncommercial License which permits any noncommercial use, distribution, and reproduction in any medium, provided the original author(s) and source are credited.

\section{References}

1. Fuentes JM, Hanly EJ, Aurora AR, De Maio A, Shih SP, Marohn MR, Talamini MA (2006) C02 Abdominal insufflation pretreatment increases survival after a lipopolysaccharide-contaminated laparotomy. J Gastrointest Surg 10:32-38

2. Bachman SL, Hanly EJ, Nwanko JI, Lamb J, Herring AE, Marohn MR, De Maio A, Talamini MA (2004) The effect of timing of pneumoperitoneum on the inflammatory response. Surg Endosc 18:1640-1644

3. Mendoza-Sagaon M, Kutka MF, Talamini MA, Poulose BK, Herreman-Suquet K, de Maio A, Paidas CN (2001) Laparoscopic Nissen fundoplication with carbon dioxide pneumoperitoneum preserves cell-mediated immunity in an immature animal model. J Pediatr Surg 36:1564-1568

4. The Southern Surgeons Club (1991) A prospective analysis of 1, 518 laparoscopic cholecystectomies. N Engl J Med 324:10731078

5. Steiner CA, Bass EB, Talamini MA, Pitt HA, Steinberg EP (2004) Surgical rates and operative mortality for open and laparoscopic cholecystectomy in Maryland. N Engl J Med 330:403-408

6. Novitsky YW, Litwin DE, Callery MP (2004) The net immunologic advantage of laparoscopic surgery. Surg Endosc 18:1411-1419

7. Weeks JC, Nelson H, Gelber S, Sargent D, Schroeder G, Clinical Outcomes of Surgical Therapy (COST) Study Group (2002) Short-term quality-of-life outcomes following laparoscopicassisted colectomy vs. open colectomy for colon cancer: a randomized trial. JAMA 287:321-328

8. Johnstone PA, Rohde DC, Swartz SE, Fetter JE, Wexner SD (1996) Port-site recurrences after laparoscopic and thoracoscopic procedures in malignancy. J Clin Onco 1(14):1950-1956

9. Champault GG, Barrat C, Raselli R, Elizalde A, Catheline JM (2002) Laparoscopic versus open surgery for colorectal carcinoma: a prospective clinical trial involving 157 cases with a mean follow-up of 5 years. Surg Laparosc Endosc Percutan Tech 12:88-95
10. Liang JT, Huang KC, Lai HS, Lee PH, Sun CT (2007) Oncologic results of laparoscopic versus conventional open surgery for stage II or III left-sided colon cancers: a randomized controlled trial. Ann Surg Onco 1(14):109-117

11. Nielsen HJ, Pedersen BK, Moesgaard F (1989) Effect of ranitidine on postoperative suppression of natural killer cell activity and delayed hypersensitivity. Acta Chir Scand 155:377-382

12. Christou NV, Superina R, Broadhead M, Meakins J (1982) Postoperative depression of host resistance: determinants and effect of peripheral protein-sparing therapy. Surgery 92:786-792

13. Nielsen HJ, Moesgaard F, Kehlet H (1989) Ranitidine for prevention of postoperative suppression of delayed hypersensitivity. Am J Surg 157:291-294

14. Hjortso NC, Kehlet H (1986) Influence of surgery, age, and serum albumin on delayed hypersensitivity. Acta Chir Scand 152:175-179

15. Lennard TW, Shenton BK, Borzotta A, Donnelly PK, White M, Gerrie LM, Proud G, Taylor RM (1985) The influence of surgical operations on components of the human immune system. Br J Surg 72:771-776

16. Allendorf JD, Bessler M, Whelan RL, Trokel M, Laird DA, Terry MB, Treat MR (1996) Better preservation of immune function after laparoscopic-assisted versus open bowel resection in a murine model. Dis Colon Rectum 39:67-72

17. Whelan RL, Franklin M, Holubar SD, Donahue J, Fowler R, Munger C, Doorman J, Balli JE, Glass J, Gonzalez JJ, Bessler M, Xie H, Treat M (2003) Postoperative cell-mediated immune response is better preserved after laparoscopic versus open colorectal resection in humans. Surg Endosc 17:972-978

18. Kirman I, Belizon A, Balik E, Feingold D, Arnell T, Horst P, Kumara S, Cekic V, Jain S, Nasar A, Whelan RL (2007) Perioperative sargramostim (recombinant human GM-CSF) induces an increase in the level of soluble VEGFR1 in colon cancer patients undergoing minimally invasive surgery. Eur J Surg Oncol 33:1169-1176

19. Bruce DM, Smith M, Walker CB, Heys SD, Binnie NR, Gough DB, Broom J, Eremin O (1999) Minimal access surgery for cholelithiasis induces an attenuated acute phase response. Am J Surg 178:232-234

20. Kloosterman T, von Blomberg BM, Borgstein P, Cuesta MA, Scheper RJ, Meijer S (1994) Unimpaired immune functions after laparoscopic cholecystectomy. Surgery 115:424-428

21. Dionigi R, Dominioni L, Benevento A, Giudice G, Cuffari S, Bordone N, Caravati F, Carcano G, Gennari R (1994) Effects of surgical trauma of laparoscopic vs. open cholecystectomy. Hepatogastroenterology 41:471-476

22. Schietroma M, Carlei F, Mownah A, Franchi L, Mazzotta C, Sozio A, Amicucci G (2004) Changes in the blood coagulation, fibrinolysis, and cytokine profile during laparoscopic and open cholecystectomy. Surg Endosc 18:1090-1096

23. Jakeways MS, Mitchell V, Hashim IA, Chadwick SJ, Shenkin A, Green CJ, Carli F (1994) Metabolic and inflammatory responses after open or laparoscopic cholecystectomy. Br J Surg 81:127-131

24. Sietses C, Wiezer MJ, Eijsbouts QA, Beelen RH, van Leeuwen PA, von Blomberg BM, Meijer S, Cuesta MA (1999) A prospective randomized study of the systemic immune response after laparoscopic and conventional Nissen fundoplication. Surgery 126:5-9

25. Perttila J, Salo M, Ovaska J, Gronroos J, Lavonius M, Katila A, Lahteenmaki M, Pulkki K (1999) Immune response after laparoscopic and conventional Nissen fundoplication. Eur J Surg 165:21-28

26. Leung KL, Tsang KS, Ng MH, Leung KJ, Lai PB, Lee JF, Lau WY (2003) Lymphocyte subsets and natural killer cell cytotoxicity after laparoscopically assisted resection of rectosigmoid carcinoma. Surg Endosc 17:1305-1310 
27. Ordemann J, Jacobi CA, Schwenk W, Stosslein R, Muller JM (2001) Cellular and humoral inflammatory response after laparoscopic and conventional colorectal resections. Surg Endosc 15:600-608

28. Nishiguchi K, Okuda J, Toyoda M, Tanaka K, Tanigawa N (2001) Comparative evaluation of surgical stress of laparoscopic and open surgeries for colorectal carcinoma. Dis Colon Rectum $44: 223-230$

29. Hildebrandt U, Kessler K, Plusczyk T, Pistorius G, Vollmar B, Menger MD (2003) Comparison of surgical stress between laparoscopic and open colonic resections. Surg Endosc 17:242246

30. Wu FPK, Sietses C, von Blomberg BME, van Leeuwen PAM, Meijer S, Cuesta MA (2003) Systemic and peritoneal inflammatory response after laparoscopic or conventional colon resection in cancer patients. Dis Colon Rectum 46:147-155

31. Braga M, Vignali A, Zuliani W, Radaelli G, Gianotti L, Martani C, Toussoun G, Di Carlo V (2002) Metabolic and functional results after laparoscopic colorectal surgery. Dis Colon Rectum 45:1070-1077

32. Kirman I, Poltaratskaia N, Cekic V, Forde KA, Ansari P, Boulay C, Whelan RL (2004) Depletion of circulating insulin-like growth factor binding protein 3 after open surgery is associated with high interleukin-6 levels. Dis Colon Rectum 47:911-917 discussion 917-918

33. Harmon GD, Senagore AJ, Kilbride MJ, Warzynski MJ (1994) Interleukin-6 response to laparoscopic and open colectomy. Dis Colon Rectum 37:754-759

34. Schwenk W, Jacobi C, Mansmann U, Bohm B, Muller JM (2000) Inflammatory response after laparoscopic and conventional colorectal resections: results of a prospective randomized trial. Langenbecks Arch Surg 385:2-9

35. Fukushima R, Kawamura YJ, Saito H, Saito Y, Hashiguchi Y, Sawada T, Muto T (1996) Interleukin-6 and stress hormone response after uncomplicated gasless laparoscopic-assisted and open sigmoid colectomy. Dis Colon Rectum 39(Suppl):s29-s34

36. Decker D, Schondorf M, Bidlingmaier F, Hirner A, von Ruecker AA (1996) Surgical stress induces a shift in the type-1/type-2 Thelper cell balance, suggesting down regulation of cell-mediated and upregulation of antibody-mediated immunity commensurate to the trauma. Surg 119:316-325

37. Kirman I, Cekic V, Poltaratskaia N et al (2003) The percentage of CD31+ T-cells decreases after open but not laparoscopic surgery. Surg Endosc 17:754-757

38. Sylla P, Nihalani A, Whelan RL (2006) Microarray analysis of the differential effects of open and laparoscopic surgery on murine splenic T-cells. Surgery 139:92-103

39. Lee SW, Feingold DL, Carter JJ, Zhai C, Stapleton G, Gleason N, Whelan RL (2003) Peritoneal macrophage and blood monocyte functions after open and laparoscopic-assisted cecectomy in rats. Surg Endosc 17:1996-2002

40. Collet D, Vitale GC, Reynods M, Klar E, Cheadle WG (1995) Peritoneal host defenses are less impaired by laparoscopy than by open operation. Surg Endosc 9:1059-1064

41. Wichmann MW, Huttl TP, Winter H, Spelsberg F, Angele MK, Heiss MM, Jauch KW (2005) Immunological effects of laparoscopic vs. open colorectal surgery: a prospective clinical study. Arch Surg 140:692-697

42. Novitsky YW, Czerniach DR, Kaban GK, Bergner A, Gallagher KA, Perugini RA, Litwin DE (2006) Immunologic effects of hand-assisted surgery on peritoneal macrophages: comparison to open and standard laparoscopic approaches. Surgery 139:39-45

43. Lacy AM, Garcia-Valdecasas JC, Delgardo S, Castells A, Taurá P, Piqué JM, Visa J (2002) Laparoscopically-assisted colectomy versus open colectomy for treatment of nonmetastatic colon cancer: a randomised trial. Lancet 359:2224-2229
44. Watson RWG, Redmond HP, McCarthy J, Burke PE, Hayes DB (1995) Exposure of the peritoneal cavity to air regulates early inflammatory responses to surgery in a murine model. Br J Surg 82:1060-1065

45. Heys SD, Deehan DJ, Eremin O (1994) Interleukin-2 treatment in colorectal cancer: current results and future prospects. Eur J Surg Oncol 20:622-629

46. Hill ADK, Redmond HP, Naama HA, Bouchier-Hayes D (1996) Granulocyte-macrophage colony stimulating factor inhibits tumor growth during the postoperative period. Surgery 119:178185

47. Mels AK, Statius Muller MG, van Leeuwen PA, von Blomberg BM, Scheper RJ, Cuesta MA, Beelen RH, Meijer S (2001) Immune-stimulating effects of low-dose perioperative recombinant granulocyte-macrophage colony-stimulating factor in patients operated on for primary colorectal carcinoma. Br J Surg 88:539-544

48. Belizon A, Horst P, Balik E, Feingold D, Arnell T, Azarani T, Cekic V, Skitt R, Kumara S, Whelan RL (2008) Persistent elevation of plasma VEGF levels during the first month following minimally invasive colorectal resection. Surg Endosc 22:287-297

49. Kirman I, Cekic V, Poltoratskaia N, Sylla P, Jain S, Forde KA, Whelan RL (2005) Open surgery induces a dramatic decrease in circulating intact IGFBP-3 in patients with colorectal cancer not seen with laparoscopic surgery. Surg Endosc 19:55-59

50. Kirman I, Cekic V, Poltaratskaia N, Asi Z, Huang EH, Forde KA, Bessler M, Whelan RL (2002) Plasma from patients undergoing major open surgery stimulates in vitro tumor growth: lower IGF-BP3 levels may, in part, account for this change. Surgery 132:186-192

51. Kirman I, Jain S, Cekic V, Belizon A, Balik E, Sylla P, Arnell T, Forde KA, Whelan RL (2006) Altered plasma matrix metalloproteinase-9/tissue inhibitor of matrix [corrected] metalloproteinase- 1 concentration during the early postoperative period in patients with colorectal cancer. Surg Endosc 20:482-486

52. Werther K, Christensen IJ, Brunner N, Nielsen HJ (2000) Soluble vascular endothelial growth factor levels in patients with primary colorectal carcinoma. The Danish RANX05 colorectal cancer study group. Eur J Surg Oncol 26:657-662

53. Ikeda M, Furukawa H, Imamura H, Shimizu J, Ishida H, Masutani S, Tatsuta M, Kawasaki T, Satomi T (2002) Surgery for gastric cancer increases plasma levels of vascular endothelial growth factor and von Willebrand factor. Gastric Cancer 5:137141

54. Karayiannakis AJ, Syrigos KN, Zbar A, Baibas N, Polychronidis A, Simopoulos C, Karatzas G (2002) Clinical significance of preoperative serum vascular endothelial growth factor levels in patients with colorectal cancer and the effect of tumor surgery. Surgery 131:548-555

55. Kumara S, Hoffman A, Nasar A, Belizon A, Baxter R, Jain S, Feingold D, Arnell T, Marodi D, Whelan RL (2007) Colorectal resection, open more so than minimally invasive in patients with benign indications is associated with proangiogenic changes in the plasma levels of angiopoietin 1 and 2. Surg Endosc 21:S352-S482

56. Kumara S, Whelan RL (unpublished data)

57. Temple LK, Litwin DE, McLeod RS (1999) A metaanalysis of laparoscopic versus open appendectomy in patients suspected of having acute appendicitis. Can J Surg 42:377-383

58. Schwenk W, Haase O, Neudecker J, Muller JM (2005) Shortterm benefits for laparoscopic colorectal resection. Cochrane Database of Systematic Reviews (3):CD003145

59. Abraham NS, Young JM, Solomon MJ (2004) Metaanalysis of short-term outcomes after laparoscopic resection for colorectal cancer. Br J Surg 91:1111-1124 
60. Tjandra JJ, Chan MK (2006) Systematic review on the shortterm outcome of laparoscopic resection for colon and rectosigmoid cancer. Colorectal Dis 8:375-388

61. Nguyen NT, Goldman C, Rosenquist CJ, Arango A, Cole CJ, Lee SJ, Wolfe BM (2001) Laparoscopic versus open gastric bypass: a randomized study of outcomes, quality of life, and costs. Ann Surg 234:279-289 discussion 289-291

62. Duepree HJ, Senagore AJ, Delaney CP, Fazio VW (2003) Does means of access affect the incidence of small bowel obstruction and ventral hernia after bowel resection? Laparoscopy versus laparotomy. J Am Coll Surg 197:177-181

63. McGreevy JM, Goodney PP, Birkmeyer CM, Finlayson SR, Laycock WS, Birkmeyer JD (2003) A prospective study comparing the complication rates between laparoscopic and open ventral hernia repairs. Surg Endosc 17:1778-1780

64. Keus F, de Jong JA, Gooszen HG, van Laarhoven CJ (2006) Laparoscopic versus open cholecystectomy for patients with symptomatic cholecystolithiasis. Cochrane Database of Systematic Reviews (4):CD006231

65. Catarci M, Gentileschi P, Papi C, Carrara A, Marrese R, Gaspari AL, Grassi GB (2004) Evidence-based appraisal of antireflux fundoplication. Ann Surg 239:325-337

66. Basse L, Jakobsen DH, Bardram L, Billesbolle P, Lund C, Mogensen T, Rosenberg J, Kehlet H (2005) Functional recovery after open versus laparoscopic colonic resection: a randomized, blinded study. Ann Surg 241:416-423

67. King PM, Blazeby JM, Ewings P, Longman RJ, Kipling RM, Franks PJ, Sheffield JP, Evans LB, Soulsby M, Bulley SH, Kennedy RH (2006) The influence of an enhanced recovery programme on clinical outcomes, costs, and quality of life after surgery for colorectal cancer. Colorectal Dis 8:506-513

68. MacKay G, Ihedioha U, McConnachie A, Serpell M, Molloy R, O'Dwyer P (2007) Laparoscopic colonic resection in fast-track patients does not enhance short-term recovery after elective surgery. Dis Colon Rectum Colorectal Dis 9:368-372

69. Guillou PJ, Quirke P, Thorpe H, Walker J, Jayne DG, Smith AM, Heath RM, Brown JM, MRC CLASICC Trial Group (2005) Short-term end points of conventional versus laparoscopic-assisted surgery in patients with colorectal cancer (MRC CLASICC trial): multicenter, randomized controlled trial. Lancet 365:1718-1726

70. Hazebroek EJ (2002) COLOR: a randomized clinical trial comparing laparoscopic and open resection for colon cancer. Surg Endosc 16:949-953

71. Noel J, Fahrbach K, Estok R, Cella C, Frame D, Linz H, Cima R, Dozois EJ, Senagore A (2007) Minimally invasive colorectal resection outcomes: short-term comparison with open procedures. J Am Coll Surg 204:291-307

72. Reza MM, Blasco JA, Andradas E, Cantero R, Mayol J (2006) Systematic review of laparoscopic versus open surgery for colorectal cancer. Br J Surg 93:921-928

73. Marusch F, Gastinger I, Schneider C, Scheidbach H, Konradt J, Bruch HP, Köhler L, Bärlehner E, Köckerling F, Laparoscopic Colorectal Surgery Study Group (LCSSG) (2001) Importance of conversion for results obtained with laparoscopic colorectal surgery. Dis Colon Rectum 44:207-214 discussion 14-16

74. Senagore AJ, Delaney CP, Madboulay K, Brady KM, Fazio VW (2003) Laparoscopic colectomy in obese and nonobese patients. J Gastrointest Surg 7:558-561

75. Moloo H, Bedard EL, Poulin EC, Mamazza J, Gregoire R, Schlachta CM (2006) Palliative laparoscopic resections for stage IV colorectal cancer. Dis Colon Rectum 49:213-218

76. Macleod R (2005) Email communication. ASCRS Listserv 2005

77. Cecil TD, Taffinder N, Gudgeon AM (2006) A personal view on laparoscopic rectal cancer surgery. Colorectal Dis 8(Suppl 3):30-32
78. Morino M, Parini U, Giraudo G, Salval M, Brachet Contul R, Garrone C (2003) Laparoscopic total mesorectal excision: a consecutive series of 100 patients. Ann Surg 237:335-342

79. Leroy J, Jamali F, Forbes L, Smith M, Rubino F, Mutter D, Marescaux J (2004) Laparoscopic total mesorectal excision (TME) for rectal cancer surgery: long-term outcomes. Surg Endosc 18(2):281-289

80. Rattner D (2006) Innovation, disruption, and the perils of success. Surg Endosc 20:1802-1808

81. Patel AN, Buenaventura PO (2005) Current staging of esophageal carcinoma. Surg Clin North Am 85:555-567

82. Luketich JD, Meehan M, Nguyen NT, Christie N, Weigel T, Yousem S, Keenan RJ, Schauer PR (2000) Minimally invasive surgical staging for esophageal cancer. Surg Endosc 14:700-702

83. Abdalla EK, Pisters PW (2004) Staging and preoperative evaluation of upper gastrointestinal malignancies. Semin Oncol 31:513-529

84. Ribeiro A, Franceschi D, Parra J, Livingstone A, Lima M, Hamilton-Nelson K, Ardalan B (2006) Endoscopic ultrasound restaging after neoadjuvant chemotherapy in esophageal cancer. Am J Gastroenterol 101:1216-1221

85. Das A, Chak A (2003) Role of endoscopic ultrasonography in the staging of esophageal cancer: a review. Curr Opin Gastroenterol 19:474-476

86. McGrath K, Brody D, Luketich J, Khalid A (2006) Detection of unsuspected left hepatic lobe metastases during EUS staging of cancer of the esophagus and cardia. Am J Gastroenterol 101:1742-1746

87. Sarela AI, Lefkowitz R, Brennan MF, Karpeh MS (2006) Selection of patients with gastric adenocarcinoma for laparoscopic staging. Am J Surg 191:134-138

88. Trivers KF, Sabatino SA, Stewart SL (2008) Trends in esophageal cancer incidence by histology, United States, 1998-2003. Int J Cancer 123:1422-1428

89. Lukanitch JM (2003) Section I: epidemiological review. Semin Thorac Cardiovasc Surg 15:158-162

90. Daly JM, Karnell LH, Menck HR (1996) National cancer data base report of esophageal cancer. Cancer 78:1820-1828

91. Brown LM, Devesa SS (2002) Epidemiologic trends in esophageal and gastric cancer in the United States. Surg Oncol Clin North Am 11:235-256

92. Medical Research Council Oesophageal Cancer Working Group (MRC OEO2) (2002) Surgical resection with or without preoperative chemotherapy in oesophageal cancer: a randomised controlled trial. Lancet 359:1727-1733

93. Gebski V, Burmeister B, Smithers BM, Foo K, Zulcberg J, Simes J (2007) Survival benefits from neoadjuvant chemoradiotherapy or chemotherapy in oesophageal carcinoma: a metaanalysis. Lancet Oncol 8:226-234

94. Weber WA, Ott K, Becker K, Dittler HJ, Helmberger H, Avril NE, Meisetschläger G, Busch R, Siewert JR, Schwaiger M, Fink U (2001) Prediction of response to preoperative chemotherapy in adenocarcinomas of the esophagogastric junction by metabolic imaging. J Clin Oncol 19:3058-3065

95. Wieder HA, Ott K, Lordick F, Becker K, Stahl A, Herrmann K, Fink U, Siewert JR, Schwaiger M, Weber WA (2007) Prediction of tumor response by FDG-PET: comparison of the accuracy of single and sequential studies in patients with adenocarcinomas of the esophagogastric junction. Eur J Nucl Med Mol Imaging 34:1925-1932

96. Lawrence W, Menck H, Steele G, Winchester D (1994) The national cancer database report on gastric cancer. Cancer 75:1737-1743

97. Cunningham D, Allum WH, Stenning SP et al (2006) Perioperative chemotherapy versus surgery alone for resectable gastroesophageal cancer. N Engl J Med 355:11-20 
98. Hewlett A (1900) The superficial glands of the esophagus. J Exp Med 5:319

99. Umar S, Fleischer DE (2008) Esophageal cancer: epidemiology, pathogenesis, and prevention. Nat Clin Pract Gastroenterol Hepatol 5:517-526

100. Trivers KF, Sabatino SA, Stewart SL (2008) Trends in esophageal cancer incidence by histology, United States, 1998-2003. Int J Cancer 23:1422-1428

101. DeMeester SR (2006) Adenocarcinoma of the esophagus and cardia: a review of the disease and its treatment. Ann Surg Oncol 13:12-16

102. Akiyama H, Tsurumaru M, Kawamura T, Ono Y (1982) Esophageal stripping with preservation of the vagus nerve. Int Surg 67:125-128

103. Banki F, Mason RJ, DeMeester SR, Hagen JA, Balaji NS, Crookes PF, Bremner CG, Peters JH, DeMeester TR (2002) Vagal-sparing esophagectomy: a more physiologic alternative. Ann Surg 236:324-335 discussion 335-336

104. Maish MS, DeMeester SR (2004) Endoscopic mucosal resection as a staging technique to determine the depth of invasion of esophageal adenocarcinoma. Ann Thorac Surg 78:1777-1782

105. Hagen JA, DeMeester SR, Peters JH, Chandrasoma P, DeMeester TR (2001) Curative resection for esophageal adenocarcinoma: analysis of 100 en bloc esophagectomies. Ann Surg 234:520-530 discussion 530-531

106. Altorki N, Skinner D (2001) Should en bloc esophagectomy be the standard of care for esophageal carcinoma? Ann Surg 234:581-587

107. Omloo JM, Lagarde SM, Hulscher JB, Reitsma JB, Fockens P, van Dekken $\mathrm{H}$, Ten Kate FJ, Obertop H, Tilanus HW, van Lanschot JJ (2007) Extended transthoracic resection compared with limited transhiatal resection for adenocarcinoma of the $\mathrm{mid} /$ distal esophagus: five-year survival of a randomized clinical trial. Ann Surg 246:992-1000 discussion 1000-1001

108. Sihvo EI, Luostarinen ME, Salo JA (2004) Fate of patients with adenocarcinoma of the esophagus and the esophagogastric junction: a population-based analysis. Am J Gastroenterol 99:419-424

109. Johansson J, DeMeester TR, Hagen JA, DeMeester SR, Peters JH, Oberg S, Bremner CG (2004) En bloc vs. transhiatal esophagectomy for stage T3 N1 adenocarcinoma of the distal esophagus. Arch Surg 139:627-631 discussion 631-633

110. Rizzetto C, DeMeester SR, Hagen JA, Peyre CG, Lipham JC, DeMeester TR (2008) En bloc esophagectomy reduces local recurrence and improves survival compared with transhiatal resection after neoadjuvant therapy for esophageal adenocarcinoma. J Thorac Cardiovasc Surg 135:1228-1236

111. Headrick JR, Nichols FCIII, Miller DL, Allen MS, Trastek VF, Deschamps C, Schleck CD, Thompson AM, Pairolero PC (2002) High-grade esophageal dysplasia: long-term survival and quality of life after esophagectomy. Ann Thorac Surg 73:1697-1702; discussion 1702-1703

112. Urschel JD, Blewett CJ, Young JE, Miller JD, Bennett WF (2002) Pyloric drainage (pyloroplasty) or no drainage in gastric reconstruction after esophagectomy: a metaanalysis of randomized controlled trials. Dig Surg 19:160-164

113. Dresner SM, Wayman J, Bennet MK, Hayes N, Griffin SM (2003) A human model of duodeno-gastro-oesophageal reflux in the development of Barrett's metaplasia. BJS 90:1120-1128

114. Oh DS, Hagen JA, Chandrasoma PT, Dunst CM, Demeester SR, Alavi M, Bremner CG, Lipham J, Rizzetto C, Cote R, Demeester TR (2006) Clinical biology and surgical therapy of intramucosal adenocarcinoma of the esophagus. J Am Coll Surg 203:152-161

115. Walsh TN, Noonan N, Hollywood D (1996) A comparison of multimodal therapy and surgery for oesophageal adenocarcinoma. N Engl J Med 335:462-467
116. Urba SG, Orringer MB, Turrisi A, Iannettoni M, Forastiere A, Strawderman M (2001) Randomized trial of preoperative chemoradiation versus surgery alone in patients with locoregional oesophageal carcinoma. J Clin Oncol 19:305-313

117. Fiorica F, Di Bona D, Schepis F, Licata A, Shahied L, Venturi A, Falchi AM, Craxì A, Cammà C (2004) Preoperative chemoradiotherapy for oesophageal cancer: a systematic review and metaanalysis. Gut 53:925-930

118. Wang GQ, Jiao GG, Chang FB, Fang WH, Song JX, Lu N, Lin DM, Xie YQ, Yang L (2004) Long-term results of operation for 420 patients with early squamous cell esophageal carcinoma discovered by screening. Ann Thorac Surg 77:1740-1744

119. Rice TW, Mason DP, Murthy SC, Zuccaro G Jr, Adelstein DJ, Rybicki LA, Blackstone EH (2007) T2N0M0 esophageal cancer. J Thorac Cardiovasc Surg 133:317-324

120. Ross WA, Alkassab F, Lynch PM, Ayers GD, Ajani J, Lee JH, Bismar M (2007) Evolving role of self-expanding metal stents in the treatment of malignant dysphagia and fistulas. Gastrointest Endosc 65:70-76

121. Dallemagne B, Weerts J, Jehaes C, Markiewicz S, Lombard R (1991) Laparoscopic Nissen fundoplication: preliminary report. Surg Endosc 3:138-143

122. Ackroyd R, Watson D, Majeed A, Troy G, Treacy PJ, Stoddard CJ (2004) Randomized clinical trial of laparoscopic versus open fundoplication for gastro-oesophageal reflux disease. BJS 91:975-982

123. DeMeester TR, Bonavina L, Albertucci M (1986) Nissen fundoplication for gastroesophageal reflux disease: evaluation of primary repair in 100 consecutive patients. Ann Surg 204:9-20

124. Hunter J, Trus T, Branum G, Waring J, Wood C (1996) Physiologic approach to laparoscopic fundoplication for gastroesophageal reflux disease. Ann Surg 223:673-685

125. Luketich J, Fernando H, Christie N, Buenaventura PO, Keenan RJ, Ikramuddin S, Schauer PR (2001) Outcomes after minimally invasive esophagomyotomy. Ann Thorac Surg 72:1909-1912

126. Patti M, Pellegrini C, Horgan S, Arcerito M, Omelanczuk P, Tamburini A, Diener U, Eubanks TR, Way LW (1999) Minimally invasive surgery for achalasia: an 8-year experience with 168 patients. Ann Surg 230:587-593

127. Khajanchee Y, Kannega S, Leatherwood A, Hansen P, Swanstrom L (2005) Laparoscopic Heller myotomy with Toupet fundoplication: outcomes predictors in 121 consecutive patients. Arch Surg 140:827-833

128. Patti M, Fisichella P, Perretta S, Galvani C, Gorodner MV, Robinson T, Way LW (2003) Impact of minimally invasive surgery on the treatment of achalsia: a decade of change. J Am Coll Surg 196:698-705

129. Millikan K, Silverstein J, Hart V, Blair K, Bines S, Roberts J, Doolas A (1995) A 15-year review of esophagectomy for carcinoma of the esophagus and cardia. J Am Coll Surg 118:328332

130. Atkins B, Shah A, Hutcheson K, Mangum JH, Pappas TN, Harpole DH Jr, D'Amico TA (2004) Reducing hospital morbidity and mortality following esophagectomy. Ann Thorac Surg 78:1170-1176

131. Stahl M, Stuschke M, Lehmann N, Meyer HJ, Walz MK, Seeber S, Klump B, Budach W, Teichmann R, Schmitt M, Schmitt G, Franke C, Wilke H (2005) Chemoradiation with and without surgery in patients with locally advanced squamous cell carcinoma of the esophagus. J Clin Oncol 23:2310-2317

132. Chiu P, Chan A, Leung S, Leong HT, Kwong KH, Li MK, AuYeung AC, Chung SC, Ng EK (2005) Multicenter prospective randomized trial comparing standard esophagectomy with chemoradiotherapy for treatment of squamous esophageal cancer: early results from the Chinese University Research Group for Esophageal Cancer (CURE). J Gastrointest Surg 9:794-802 
133. Luketich J, Alvelo-Rivera M, Buenaventura P, Christie NA, McCaughan JS, Litle VR, Schauer PR, Close JM, Fernando HC (2003) Minimally invasive esophagectomy outcomes in 222 patients. Ann Surg 238:486-495

134. Collard JM, Lengele B, Otte JB, Ketsens PJ (1993) En bloc and standard esophagectomies by thoracoscopy. Ann Thorac Surg 56:675-679

135. Akaishi T, Kaneda I, Higuchi N, Kuriya Y, Kuramoto J, Toyoda T, Wakabayashi A (1996) Thoracoscopic en bloc total esophagectomy with radical mediastinal lymphadenectomy. J Thorac Cardiovasc Surg 96(112):1533-1540

136. Robertson GS, Lloyd DM, Wicks AC, Veitch (1996) No obvious advantages for thoracoscopic two-stage oesophagectomy. Br J Surg 83:675-678

137. DePaula AL, Hashiba K, Ferreira EA, de Paula RA, Grecco E (1995) Laparoscopic transhiatal esophagectomy with esophagogastroplasty. Surg Laparosc Endosc 5:1-5

138. Swanstrom L, Hansen P (1997) Laparoscopic total esophagectomy. Arch Surg 132:943

139. Bizekis C, Kent M, Buenaventura P, et al (2005) Initial experience with minimally invasive Ivor Lewis esophagectomy. Presented at the annual meeting of the southern thoracic surgical association, 10-12 November 2005. Orlando, FL

140. Cushieri A, Shimi S, Banting S (1992) Endoscopic esophagectomy through a right thoracoscopic approach. J R Coll Surg Edinb 37:7-11

141. Palanivelu C, Prakash A, Rangaswamy S, Senthilnathan P, Parthasarathi R, Rajan PS, Venkatachlam S (2006) Minimally invasive esophagectomy: thoracoscopic mobilization of the esophagus and mediastinal lymphadenectomy in prone position: an experience of 130 patients. J Am Coll Surg 203:7-16

142. Nguyen N, Follette D, Wolfe B et al (2000) Comparison of minimally invasive esophagectomy with transthoracic and transhiatal esophagectomy. Arch Surg 135:920

143. Nguyen N, Roberts P, Follette D, Rivers R, Wolfe B (2003) Thoracoscopic and laparoscopic esophagectomy for benign and malignant disease: lessons learned from 46 consecutive procedures. J Am Coll Surg 197:902-913

144. Narumiya K, Nakamura T, Ide H, Takasaki K (2005) Comparison of extended esophagectomy through mini-thoracotomy/ laparotomy with conventional thoracotomy/laparotomy for esophageal cancer. Jpn J Thorac Cardiovasc Surg 53:413-419

145. Smithers BM, Gotley DC, Martin I, Thomas JM (2007) Comparison of the outcomes between open and minimally invasive esophagectomy. Ann Surg 245:232-240

146. Braghetto I, Csendes A, Cardemil G, Burdiles P, Korn O, Valladares H (2006) Open transthoracic or transhiatal esophagectomy versus minimally invasive esophagectomy in terms of morbidity, mortality, and survival. Surg Endosc 20:1681-1686

147. Osugi H, Takemura M, Higashino M, Takada N, Lee S, Ueno M, Tanaka Y, Fukuhara K, Hashimoto Y, Fujiwara Y, Kinoshita H (2003) Learning curve of video-assisted thoracoscopic esophagectomy and extensive lymphadenectomy for squamous cell cancer of the thoracic esophagus and results. Surg Endosc 17:515-519

148. Taguchi S, Osugi H, Higashino M (2003) Comparison of threefield esophagectomy for esophageal cancer incorporating open or thoracoscopic thoracotomy. Surg Endosc 17:445-1450

149. Guilianotti P, Coratti A, Angelina M, Sbrana F, Cecconi S, Balestracci T, Caravaglios G (2003) Robotics in general surgery: personal experience in a large community hospital. Arch Surg 138:777-784

150. Bodner J, Wykypiel H, Wetscher G, Schmid T (2004) First experience with the da Vinci trademark operating robot in thoracic surgery. Eur J Cardiothor Surg 25:844-851
151. Melvin W, Needleman B, Krause K, Schneider C, Wolf RK, Michler RE, Ellison EC (2002) Computer-enhanced robotic telesurgery: initial experience in foregut surgery. Surg Endosc 16:1790-1792

152. Horgan S, Berger R, Elli E, Espat N (2003) Robotic-assisted minimally-invasive transhiatal esophagectomy. Am Surg 69:624-669

153. Jacobsen G, Espat N, Berger R (2004) A single-institution experience with robotically assisted transhiatal total esophagectomy. SAGES 2004 scientific and postgraduate courses, 31 March-3 April 2004. Denver, CO

154. Watson DI, Jamieson GG, Devitt PG (2000) Endoscopic cervicothoracoabdominal esophagectomy. J Am Coll Surg 193:372378

155. Gossot D, Cattan P, Fritsch S, Halimi, Sarfati E, Celerier M (1995) Can the morbidity of esophagectomy be reduced by the thoracoscopic approach? Surg Endosc 9:1113-1115

156. Jagot P, Sauvanet A, Berthoux L, Beghiti J (1996) Laparoscopic mobilization of the stomach for oesophageal replacement. Br J Surg 83:540-542

157. Liu HP, Ch Chang, Lin PJ, Chang JP (1995) Video-assisted endoscopic esophagectomy with stapled intrathoracic esophagogastric anastomosis. World J Surg 19:745-747

158. Peracchia A, Rosati R, Fumagalli U, Bona S, Chella B (1997) Thoracoscopic esophagectomy: are there benefits? Semin Surg Oncol 13:259-262

159. Law S, Fok M, Chu KM, Wong J (1997) Thoracoscopic esophagectomy for esophageal cancer. Surgery 122:8-14

160. Kawahara K, Maekawa T, Okabayashi T, Hideshima T, Shiraishi T, Yoshinaga Y, Shirakusa T (1999) Video-assisted thoracoscopic esophagectomy for esophageal cancer. Surg Endosc $13: 218-223$

161. Smithers BM, Gotley DC, McEwan D, Martin I, Bessell J, Doyle L (2001) Thoracoscopic mobilization of the esophagus: a sixyear experience. Surg Endosc 15:176-182

162. Mathisen DJ, Grillo HC, Wilkins EW, Moncure AC, Hilgenberg AD (1988) Transthoracic esophagectomy: a safe approach to carcinoma of the esophagus. Ann Thorac Surg 45:137-143

163. Lerut T, DeLeyn P, Coosemans W, Van Raemdonck D, Scheys I, LeSaffre E (1992) Surgical strategies in esophagealcarcinoma with emphasis on radical lymphadenectomy. Ann Surg 216:583590

164. Orringer MB, Marshall B, Iannettoni MD (1999) Transhiatal esophagectomy: clinical experience and refinements. Ann Surg 230:392-403

165. Swanson SJ, Batirel HF, Bueno R, Jaklitsch MT, Lukanich JM, Allred E, Mentzer SJ, Sugarbaker DJ (2001) Transthoracic esophagectomy with radical mediastinal and abdominal lymph node dissection and cervical esophagogastrostomy for esophageal carcinoma. Ann Thorac Surg 72:1918-1925

166. Bailey SH, Bull DA, Harpole DH, Rentz JJ, Neumayer LA, Pappas TN, Daley J, Henderson WG, Krasnicka B, Khuri SF (2003) Outcomes after esophagectomy: a ten-year prospective cohort. Ann Thorac Surg 75:217-222

167. Rizk NP, Bach PB, Schrag D, Bains MS, Turnbull AD, Karpeh M, Brennan MF, Rusch VW (2004) The impact of complications on outcomes after resection for esophageal and gastroesophageal junction carcinoma. J Am Coll Surg 198:42-50

168. Maruyama K, Gunven P, Okabayashi K, Sasako M, Kinoshita T (1989) Lymph node metastases of gastric cancer: general pattern in 1, 931 patients. Ann Surg 210:596-602

169. Kitajima M (2005) Strategies for gastric cancer treatment in the twenty-first century: minimally invasive and tailored approaches integrating basic science and clinical medicine. Gastric Cancer 8:55-58 
170. Siewert JR, Kestlmeier R, Busch R, Böttcher K, Roder JD, Müller J, Fellbaum C, Höfler H (1996) Benefits of D2 lymph node dissection for patients with gastric cancer and $\mathrm{pN0}$ and pN1 lymph node metastases. Br J Surg 83:1144-1147

171. Maruyama K, Sasako M, Kinoshita T, Sano T, Katai H, Okajima K (1995) Pancreas-preserving total gastrectomy for proximal gastric cancer. World J Surg 19:532-536

172. Griffith JP, Sue-Ling HM, Martin I et al (1995) Preservation of the spleen improves survival after radical surgery for gastric cancer. Gut 36:684-690

173. Hartgrink HH, van de Velde CJ, Putter H, Bonenkamp JJ, Klein Kranenbarg E, Songun I, Welvaart K, van Krieken JH, Meijer S, Plukker JT, van Elk PJ, Obertop H, Gouma DJ, van Lanschot JJ, Taat CW, de Graaf PW, von Meyenfeldt MF, Tilanus H, Sasako M (2004) Extended lymph node dissection for gastric cancer: who may benefit? Final results of the randomized Dutch gastric cancer group trial. J Clin Oncol 22:2069-2077

174. Bonenkamp JJ, Hermans JS, M van De Velde CJH (1999) Extended lymph node dissection for gastric cancer. N Engl J Med 340

175. Sarela AI, Turnbull AD, Coit DG, Klimstra D, Brennan MF, Karpeh MS (2003) Accurate lymph node staging is of greater prognostic importance than subclassification of the T2 category for gastric adenocarcinoma. Ann Surg Oncol 10:783-791

176. Macdonald JS, Smalley SR, Benedetti J, Hundahl SA, Estes NC, Stemmermann GN, Haller DG, Ajani JA, Gunderson LL, Jessup JM, Martenson JA (2001) Chemoradiotherapy after surgery compared with surgery alone for adenocarcinoma of the stomach or gastroesophageal junction. N Engl J Med 345:725-730

177. Hundahl SA, Macdonald JS, Benedetti J, Fitzsimmons T (2002) Surgical treatment variation in a prospective, randomized trial of chemoradiotherapy in gastric cancer: the effect of undertreatment. Ann Surg Oncol 9:278-286

178. Yamaguchi T, Sano T, Katai H, Sasako M, Maruyama K (2001) Node-positive mucosal gastric cancer: a follow-up study. Jpn J Clin Oncol 31:153

179. Dent DM, Madden MV, Price SK (1988) Randomized comparison of R1 and R2 gastrectomy for gastric carcinoma. Br J Surg 75:110-112

180. Robertson CS, Chung SC, Woods SD, Griffin SM, Raimes SA, Lau JT, Li AK (1994) A prospective randomized trial comparing R1 subtotal gastrectomy with R3 total gastrectomy for antral cancer. Ann Surg 220:176-182

181. Cuschieri A, Fayers P, Fielding J, Craven J, Bancewicz J, Joypaul V, Cook P (1996) Postoperative morbidity and mortality after D1 and D2 resections for gastric cancer: preliminary results of the MRC randomised controlled surgical trial. The surgical cooperative group. Lancet 347:995-999

182. Degiuli M, Sasako M, Calgaro M, Garino M, Rebecchi F, Mineccia M, Scaglione D, Andreone D, Ponti A, Calvo F, Italian Gastric Cancer Study Group (2004) Morbidity and mortality after D1 and D2 gastrectomy for cancer: interim analysis of the Italian Gastric Cancer Study Group (IGCSG) randomised surgical trial. Eur J Surg Oncol 30:303-308

183. Sano T, Sasako M, Yamamoto S, Nashimoto A, Kurita A, Hiratsuka M, Tsujinaka T, Kinoshita T, Arai K, Yamamura Y, Okajima K (2004) Gastric cancer surgery: morbidity and mortality results from a prospective randomized controlled trial comparing D2 and extended para-aortic lymphadenectomyJapan clinical oncology group study 9501. J Clin Oncol 22:2767-2773

184. Huscher CG, Mingoli A, Sgarzini G, Sansonetti A, Di Paola M, Recher A, Ponzano C (2005) Laparoscopic versus open subtotal gastrectomy for distal gastric cancer: five-year results of a randomized prospective trial. Ann Surg 241:232-237

185. Aiko T, Sasako M (1998) The new Japanese classification of gastric carcinoma: points to be revised. Gastric Cancer 1:25-30

186. Japanese Gastric Cancer Association (2002) JGCA gastric cancer treatment guidelines. Kanehara \& Co, Ltd, Tokyo

187. Uyama I, Sugioka A, Fujita J, Komori Y, Matsui H, Soga R, Wakayama A, Okamoto K, Ohyama A, Hasumi A (1999) Completely laparoscopic extraperigastric lymph node dissection for gastric malignancies located in the middle or lower third of the stomach. Gastric Cancer 2:186-190

188. Uyama I, Sugioka A, Matsui H, Fujita J, Komori Y, Hasumi A (2000) Laparoscopic D2 lymph node dissection for advanced gastric cancer located in the middle or lower third portion of the stomach. Gastric Cancer 3:50-55

189. Uyama I, Sugioka A, Fujita J, Komori Y, Matsui H, Hasumi A (1999) Laparoscopic total gastrectomy with distal pancreatosplenectomy and D2 lymphadenectomy for advanced gastric cancer. Gastric Cancer 2:230-234

190. Uyama I, Sugioka A, Matsui H, Fujita J, Komori Y, Hasumi A (2001) Laparoscopic pancreas-preserving total gastrectomy for proximal gastric cancer: a case and technical report. Surg Endosc 15:217-218

191. Kent MS, Schuchert M, Fernando H, Luketich JD (2006) Minimally invasive esophagectomy: state of the art. Dis Esophagus 19(3):137-145. Review 